\title{
In vivo anticancer evaluation of the hyperthermic efficacy of anti-human epidermal growth factor receptor-targeted PEG-based nanocarrier containing magnetic nanoparticles
}

This article was published in the following Dove Press journal:

International Journal of Nanomedicine

24 June 2014

Number of times this article has been viewed

\author{
Giovanni Baldi' \\ Costanza Ravagli' \\ Filippo Mazzantini' \\ George Loudos ${ }^{2}$ \\ Jaume Adan ${ }^{3}$ \\ Marc Masa ${ }^{3}$ \\ Dimitrios Psimadas ${ }^{2}$ \\ Eirini A Fragogeorgi ${ }^{2}$ \\ Erica Locatelli ${ }^{4}$ \\ Claudia Innocenti ${ }^{5,6}$ \\ Claudio Sangregorio ${ }^{5,7}$ \\ Mauro Comes Franchini ${ }^{4}$ \\ 'CERICOL, Sovigliana-Vinci, Italy; \\ ${ }^{2}$ Technological Educational Institute \\ of Athens, Athens, Greece; ${ }^{3}$ Leitat \\ Technological Center, Barcelona, \\ Spain; ${ }^{4}$ Department of Industrial \\ Chemistry Toso Montanari, University \\ of Bologna, Bologna, ${ }^{5}$ Consorzio \\ Interuniversitario Nazionale \\ per la Scienza e Tecnologia dei \\ Materiali (INSTM), ${ }^{6}$ Dipartimento \\ di Chimica U Schiff, Università di \\ Firenze, Firenze, ${ }^{7}$ Centro Nazionale \\ delle Ricerche (ICCOM - CNR), \\ Firenze, Italy
}

\begin{abstract}
Polymeric nanoparticles with targeting moieties containing magnetic nanoparticles as theranostic agents have considerable potential for the treatment of cancer. Here we report the chemical synthesis and characterization of a poly(D,L-lactide-co-glycolide)- $b$-poly(ethylene glycol)-based nanocarrier containing iron oxide nanoparticles and human epithelial growth factor receptor on the outer shell. The nanocarrier was also radiolabeled with ${ }^{99 \mathrm{~m}} \mathrm{Tc}$ and tested as a theranostic nanomedicine, ie, it was investigated for both its diagnostic ability in vivo and its therapeutic hyperthermic effects in a standard A431 human tumor cell line. Following radiolabeling with ${ }^{99 \mathrm{~m}} \mathrm{Tc}$, the biodistribution and therapeutic hyperthermic effects of the nanosystem were studied noninvasively in vivo in tumor-bearing mice. A substantial decrease in tumor size correlated with an increase in both nanoparticle concentration and local temperature was achieved, confirming the possibility of using this multifunctional nanosystem as a therapeutic tool for epidermoid carcinoma.
\end{abstract}

Keywords: magnetic nanoparticles, polymeric nanocarriers, skin cancer, hyperthermia, singlephoton emission computed tomography, imaging

\section{Introduction}

As a result of their novel intrinsic physical properties, there has been considerable interest in the development of a variety of functional inorganic nanoparticles for use in biomedical technology. ${ }^{1-3}$ Of particular significance are magnetic nanoparticles, which have the advantages of being able to be visualized by magnetic resonance imaging (MRI), guided to target sites by an external magnetic field, and heated to provide hyperthermia/ablation cancerous tissues, ie, magnetic fluid hyperthermia. ${ }^{4-11}$ In order to fully exploit their potential, magnetic nanoparticles are often engineered by conjugation with biomolecules to target specific cells. The scientific community is seeking to obtain medical breakthroughs in diagnosis and therapy, ${ }^{12,13}$ giving rise to the concept of theranostics. ${ }^{14-16}$

Magnetic fluid hyperthermia is induced by the response of superparamagnetic nanoparticles to an alternating magnetic field, the energy of which is absorbed by the system and then converted into heat. The general clinical idea is to use locally generated heat to destroy tumors, limiting the side effects at the frequencies used in magnetic fluid hyperthermia $(50-500 \mathrm{kHz})$. Importantly, the magnetic field is not absorbed by living tissues. There have been very few published reports thus far of their use in patients, ${ }^{17,18}$ even if recently more focused hyperthermic studies for biomedical applications have begun to arise and have been reported due to the extremely interesting perspectives.
Correspondence: Mauro Comes Franchini Department of Industrial Chemistry Toso Montanari,Viale Risorgimento 4, 40I36, Bologna, Italy

Tel +5I 2093626

Fax +5I 2093654

Email mauro.comesfranchini@unibo.it 
The hyperthermia effect obtained by applying an alternating magnetic field to HeLa cells incubated with an aqueous suspension of $\gamma-\mathrm{Mn}_{x} \mathrm{Fe}_{2-\mathrm{x}} \mathrm{O}_{3}$ was reported to cause cell death proportional to both the quantity of particles used and the duration of application of the magnetic field. ${ }^{19}$ Cheon et al ${ }^{20}$ demonstrated that zinc-doped metal ferrite nanoparticles had contrast and hyperthermic effects that were much higher than those of conventional agents such as Feridex ${ }^{\circledR}$, and more recently reported on use of cobalt-based magnetic nanoparticles as a double-effector for apoptotic hyperthermia. ${ }^{21,22}$ Kobayashi et al ${ }^{23}$ showed that anti-HER2 immunoliposomes loaded with magnetite nanoparticles under an alternating magnetic field had a strong cytotoxic effect in vitro on $\mathrm{SKBr} 3$ breast cancer cells and this was due to the targeting action of anti-HER2. Further, superparamagnetic theranostic nanoclusters with folic acid as the targeting agent have recently been described. ${ }^{4}$ Various multistimuli-responsive polymeric matrix systems loaded with magnetic nanoparticles have also been developed to enable strict control of the behavior of nanosystems. ${ }^{24-26}$ In particular, Shen et al demonstrated the possibility of triggering drug release in complex luminescent/magnetic nanosystems under magnetic guidance and near infrared irradiation in vivo. ${ }^{27-29}$

Positron emission tomography and single-photon emission computed tomography are highly sensitive functional imaging modalities, which are only used for diagnosis. ${ }^{30-32}$ Radiolabeling of carriers containing magnetic nanoparticles would provide a sensitive imaging modality allowing dynamic imaging and visualization of their route in vivo, which would facilitate faster acquisition of a more accurate biodistribution profile than that achievable by MRI. The recent introduction of simultaneous positron emission tomography/MRI ${ }^{30}$ scanners and ongoing research on single-photon emission computed tomography/MRI systems ${ }^{31}$ have opened up new prospects for the preclinical and potentially clinical application of radiolabeled magnetic nanoparticles by combining the advantages of anatomic and functional imaging. ${ }^{32}$

We have recently reported on the preparation of a system based on cobalt ferrite nanoparticles entrapped in bovine serum albumin as a theranostic agent that acts as a good negative MRI contrast agent and as a heating mediator, with an in vitro mortality rate of up to $82 \%$ in HeLa cells. ${ }^{33}$

Taking into account the toxicology and biocompatibility of the materials used, we moved from using cobalt-based nanoparticles to biocompatible superparamagnetic iron oxide nanoparticles. Here we report the entrapment of lipophilic magnetite nanoparticles into poly(ethylene glycol) (PEG)-based polymeric nanoparticles (PNPs). Owing to their stealth characteristics, ${ }^{34,35}$ these nanocarriers are useful delivery systems in vivo. Visualization of the fate of these hybrid nanoparticles targeted with a monoclonal antibody was undertaken in a mouse model of A431 epidermoid carcinoma following radiolabeling with technetium $\left({ }^{99 \mathrm{~m}} \mathrm{Tc}\right)$, a gamma photon-emitting radionuclide. To our knowledge, this is one of the first studies where high-resolution single-photon emission computed tomography imaging has been used to assess targeting in vivo, as well as provide noninvasive quantitative information on the distribution of nanoparticles in a model of A431, including the main organs. In a recent study, Misri et al used ex vivo autoradiography to measure the biodistribution of magnetic nanoparticles radiolabeled with ${ }^{111}$ In, but did not report any in vivo imaging results. ${ }^{34}$ Here, we report a proof of concept experiment in which hyperthermic treatment was used in vivo in a mouse model of A431 epidermoid carcinoma, which is the third most common type of skin cancer. ${ }^{36,37}$

\section{Materials and methods Chemicals and instruments}

All chemicals used in this study were purchased from SigmaAldrich (St Louis, MO, USA). All aqueous solutions were prepared with deionized water obtained using a Milli-Q ultrafiltration system (Millipore Corporation, Billerica, MA, USA) with a measured resistivity above $18 \mathrm{~m} \Omega .{ }^{1} \mathrm{H}$ nuclear magnetic resonance (NMR) and ${ }^{13} \mathrm{C}$ NMR spectra were recorded using $\mathrm{CDCl}_{3}$ or dimethyl sulfoxide solutions at $400 \mathrm{mHz}$ and $600 \mathrm{mHz}$ for ${ }^{1} \mathrm{H}$ and $100.6 \mathrm{mHz}$ and $150.92 \mathrm{mHz}$ for ${ }^{13} \mathrm{C}$. Infrared spectra were recorded on a model 257 grating spectrometer (PerkinElmer, Boston, MA, USA). Mass spectra were obtained using an electrospray ionization source; all electrospray ionization source mass spectra were performed using methanol as the solvent. Ultraviolet-visible spectra were recorded on a Lambda 12 spectrometer (PerkinElmer). Dynamic light scattering measurements of each sample were performed on $1-2$ cc of a $0.01 \%$ weight/weight (w/w) dispersion of particles in a quartz cuvette on a Zetasizer Nano S (Malvern Instruments, Malvern, UK) working with a $532 \mathrm{~nm}$ laser beam. Native samples were diluted to this concentration with pure dispersant. Five runs were carried out for each sample. Iron concentrations in the samples were measured by inductively coupled plasma atomic emission spectrometry (Liberty 51; Varian Medical Systems, Palo Alto, CA, USA) after dissolving the samples in concentrated nitric acid. These measurements were carried out by nebulization of solution, with an instrumental sensitivity of $0.0013 \mathrm{ppm}(\mathrm{mg} / \mathrm{L})$. 
Magnetization measurements were performed using a S600 superconducting quantum interference magnetometer (Cryogenic Ltd, London, UK) operating in the temperature range of $1.5-310 \mathrm{~K}$ and with a magnetic field of $\mathrm{H}= \pm 6.5 \mathrm{~T}$ and an MPS superconducting quantum interference magnetometer (Quantum Design Ltd, San Diego, CA, USA) operating in the temperature range of $1.7-340 \mathrm{~K}$ and with a magnetic field of $\mathrm{H}= \pm 5 \mathrm{~T}$. The crystalline structure of the samples was identified from X-ray diffraction patterns recorded in the $2 \theta$ range of $10^{\circ}-70^{\circ}$ with a scan step of $0.05^{\circ}$ (20) for 5 seconds on an X'pert Pro ( $\mathrm{Cu} \mathrm{K} \alpha$ radiation) diffractometer (Philips, Eindhoven, The Netherlands). The crystallite size was determined from the (311) diffraction peak using the Scherrer method. Scanning transmission electron microscopy was performed using a Supra 40 device (Zeiss, Oberkochen, Germany) operating at $20 \mathrm{keV}$. Energydispersive $\mathrm{X}$-ray spectroscopy was performed using an INCA $\mathrm{X}$-sight energy-dispersive spectrometer (Oxford Instruments, Abingdon, UK). The ${ }^{99} \mathrm{Mo}-{ }^{99 \mathrm{~m}} \mathrm{Tc}$ generator was obtained from Mallinckrodt Medical BV (Petten, The Netherlands) and the dose calibrator was from Capintec Instruments Inc (Pittsburgh, PA, USA). The instant thin layer chromatography sheets were purchased from Gelman Sciences (Ann Arbor, MI, USA). The Imager used for the radio instant thin layer chromatography analysis as well as the Cobra II gamma counter used for measurement of radioactivity in the biodistribution samples were from Canberra Packard Central Europe GmbH (Schwadorf, Austria).

\section{Cell line}

A431 epidermoid carcinoma cells were purchased from the American Type Culture Collection (Manassas, VA, USA). Dulbecco's Modified Eagle's Medium, penicillin 10,000 U/mL, streptomycin 10,000 $\mu \mathrm{g} / \mathrm{mL}$, L-glutamine, Dulbecco's phosphate-buffered saline, and trypsin $0.05 \%$ /ethylenediaminetetraacetic acid $0.02 \%(\mathrm{w} / \mathrm{w})$ solution were purchased from Biochrom AG (Berlin, Germany) and fetal bovine serum was obtained from Gibco/Invitrogen (Carlsbad, CA, USA).

\section{Mouse model}

The biodistribution studies were performed using normal female Swiss and severe combined immunodeficiency (SCID) mice (weighing 15-25 g) of the same colony and age, which were purchased from the breeding facilities of the National Center For Scientific Research Demokritos. Gamma camera imaging was performed using a high resolution small animal gamma camera with a $5 \times 10 \mathrm{~cm}$ field of view. This prototype system has a spatial resolution of $1.5 \mathrm{~mm}$ and an energy resolution of $15 \%$. Regions of interest were analyzed using ImageJ software (available online from http://imagej.nih.gov/ij/). ${ }^{38}$ The heat generated by the intratumorally injected nanoparticle dispersions was measured when the A431-bearing mice were placed at the center of the coil, which induces the magnetic field. The coil has 3 turns, $4.2 \mathrm{~cm}$ height and a diameter of $10 \mathrm{~cm}$, which allows the entire animal to be placed inside. Next, the tumors were exposed to a strong magnetic field for 30 minutes. An MP 6 kW instrument (Fives Celes, Lautenbach, France) was used for induction of magnetic hyperthermia. We set the magnetic field by adjusting the voltage in the power supply, the frequency with an appropriate copper coil $(\varnothing 110 \mathrm{~mm}$, three turns), and an inductor set-up $\left[\mathrm{H}_{0}=25(\mathrm{kA} / \mathrm{m}), f=173(\mathrm{kHz})\right]$. Specific absorption rates for samples in solution were estimated by measuring the temperature increase with an optical fiber probe (CEAM Vr18CR-PC) (CEAM Group, Via Val d'Orme, Italy) and evaluating the initial slope of the temperature kinetics curve. Changes in temperature during animal testing were recorded using a ThermaCAM ${ }^{\mathrm{TM}}$ E300 (FLIR) (FLIR Systems Inc., Meer, Belgium) infrared camera (FLIR Systems, Inc). All the animal studies were performed in compliance with European legislation and were approved by the relevant Greek authorities.

\section{Magnetization measurements}

Zero field-cooled/field-cooled magnetization measurements were acquired applying a 50 Oe probe field after cooling the sample from $300 \mathrm{~K}$ to $2.5 \mathrm{~K}$ in the absence (zero field-cooled) or presence (field-cooled) of the probe field. Magnetization curves were acquired at $2.5 \mathrm{~K}$ (hysteresis loops) and at $300 \mathrm{~K}$ up to a $5 \mathrm{~T}$ magnetic field. Samples in diethylene glycol or aqueous solution were sealed with gel caps to prevent evaporation of the solvent during measurement. The experimental data presented in the following were corrected by removing the diamagnetic contribution of the sample holder and solvent.

\section{Biological studies}

The antibody-producing epidermal growth factor receptor (EGFR) hybridoma cell line (HB-9764) was acquired from the American Type Culture Collection. A standard procedure was established for production, scale-up, and purification. The hybridoma was a myeloma NS-1 that produces immunoglobulin $\mathrm{G} 2 \mathrm{a}(k)$.

\section{Growth conditions}

The initial growth conditions were Dulbecco's Modified Eagle's Medium/F12, 10\% fetal bovine serum, 2 mML-Glu, $2 \mathrm{mM} \mathrm{Glu-}$ tamax, and $50 \mu \mathrm{g} / \mathrm{mL}$ gentamicin. The cells were grown in suspension. Scarce aggregates, formed by $3-5$ cells, were found. 
Doubling time was approximately 24 hours. Later, the hybridoma cell line was adapted to serum-free conditions (ie, Dulbecco's Modified Eagle's Medium/F12, 0.5\% peptone, $8 \mathrm{mM} \mathrm{L}$-Glu, and $1 \mathrm{mM}$ sodium pyruvate).

\section{Antibody secretion, hybridoma growth in serum-free conditions, and purification}

The HB-9764 hybridoma cell line is a good producer in both standard growth conditions and in serum-free medium. Productivity analysis showed values over $100 \mu \mathrm{g} / \mathrm{mL}$. The hybridoma cell line was grown in $2 \mathrm{~L}$ spinner flasks for purification of the anti-EGFR monoclonal antibody. The supernatants were filtered and concentrated before being subjected to affinity chromatography with protein A-sepharose (Pharmacia, Piscataway, NJ, USA). Eluted immunoglobulin $\mathrm{G}$ was checked by gel electrophoresis (S12) and highperformance liquid chromatography to ensure purity. The buffer solution was exchanged for phosphate-buffered saline, and the concentration was determined at OD 280 using an extinction coefficient of 1.43 . The monoclonal antibody was aliquoted and stored at $-80^{\circ} \mathrm{C}$. Electrophoresis of the purified antibody in denaturing and reduced conditions showed two bands corresponding to the light and heavy chains of the antibody. Further electrophoresis in denaturing conditions showed a single band of around $150 \mathrm{kDa}$, confirming that no contamination were present.

\section{In vivo biodistribution and hyperthermic treatment Radiobiological and imaging studies}

Biodistribution and imaging studies of $\mathrm{Fe}_{3} \mathrm{O}_{4}-1$-PNPhEGFR $-{ }^{99 \mathrm{~m}} \mathrm{Tc}$ were performed in healthy female Swiss mice and athymic SCID mice bearing A431 tumors after intravenous administration of the radiolabeled preparation $(0.03-0.05 \mathrm{mg} / \mathrm{mL})$ via the tail vein $(100 \mu \mathrm{L}, 3-5 \mathrm{mBq}$ per animal).

For implantation of the tumors in SCID mice, A431 cells freshly suspended in medium were subcutaneously injected in the left or right flank at a concentration of $5 \times 10^{6}$ cells per animal. The mice were injected when they were $4-6$ weeks of age. The tumors were allowed to grow for one week, and the volume of the subcutaneously implanted tumor was estimated using a Vernier caliper (an external morphological measurement device). Tumor volume was calculated according to the formula: largest dimension $\times(\text { smallest dimension })^{2} \times 0.52$.

For the biodistribution studies, the animals were sacrificed by ether anesthesia at 60 minutes, 90 minutes, and 24 hours post injection. Three animals were used for each time point.
All the main organs were removed, washed with $0.9 \% \mathrm{NaCl}$, paper-dried, weighed, and counted (together with samples of blood, muscle, and urine) in a gamma counter system. The results were expressed as \%ID per organ and per gram of each organ/tissue, in comparison with a standard of the injected solution. For the scintigraphic imaging studies, both healthy and tumor-bearing mice were anesthetized immediately after injection using a mixture of $0.5 \mathrm{~mL}$ of ketamine hydrochloride $(100 \mathrm{mg} / \mathrm{mL}), 0.25 \mathrm{~mL}$ of xylazine $(20 \mathrm{mg} / \mathrm{mL})$, and $4.25 \mathrm{~mL}$ of $\mathrm{NaCl} 0.9 \%$ administered intraperitoneally at $0.1 \mathrm{~mL} / 10 \mathrm{~g}$ of animal weight. Dynamic images of the injected mice were obtained from 10 minutes post injection up to at least 60 minutes post injection using the previously described high-resolution small animal gamma camera. After completion of the scintigraphic study, the animals were sacrificed by ether inhalation and included in the biodistribution studies.

\section{Intratumoral hyperthermia studies}

Six animals were randomly divided into three groups, consisting of two mice each. The first group did not undergo any invasive procedure and served as tumor growth controls. The second group received an intratumoral treatment for two successive days, with $100 \mu \mathrm{L} \mathrm{Fe}_{3} \mathrm{O}_{4}-1$-PNP-hEGFR $(4.53 \mathrm{mg} / \mathrm{mL}$ $\mathrm{Fe}_{3} \mathrm{O}_{4}$ ). The third group received an intratumoral treatment, with increased amount of the nanoparticle dispersion on days $16,17,18,19$, and 22 . The injected volume was $800 \mu \mathrm{L}$, $800 \mu \mathrm{L}, 400 \mu \mathrm{L}, 400 \mu \mathrm{L}$ and $400 \mu \mathrm{L}$, respectively, of a $4.53 \mathrm{mg} / \mathrm{mL} \mathrm{Fe}_{3} \mathrm{O}_{4}$ solution. Each injection was followed by a 30-minute exposure to an alternating magnetic field. The first mouse was exposed to an alternating magnetic field for four times in total and the intervals between the sessions were three days. The second mouse was exposed six times in total; the first four times were performed every day and the last two every three days. The tumor size was calculated daily according to the $0.5 \times$ length $\times(\text { width })^{2}$ formula.

\section{Results}

Magnetite $\left(\mathrm{Fe}_{3} \mathrm{O}_{4}\right)$ nanoparticles were synthesized according to the polyol method in diethylene glycol developed by our group for cobalt ferrites. ${ }^{16}$ When analyzed by the Scherrer equation, X-ray diffractograms for the assembly (Figure S1) showed an average crystalline diameter of $12.0 \pm 0.9 \mathrm{~nm}$. Average hydrodynamic diameter was also assessed by dynamic light scattering, which indicated a log-normal size distribution with an average particle diameter of $23.2 \pm 1.2 \mathrm{~nm}$ and a mean polydispersity index of $0.10 \pm 0.04$ (Figure S2). Transmission electron microscopy revealed an average 
particle diameter of $22 \pm 3.9 \mathrm{~nm}$, each one composed of smaller domains with an average diameter of $10 \pm 2.6 \mathrm{~nm}$ (Figure S3). The magnetic properties of the as-synthesized particles were explored by measuring the temperature and field dependence of magnetization (Figure S4). The magnetization curve at $300 \mathrm{~K}$ did not indicate hysteresis, whereas a coercive field $\left(\mathrm{H}_{\mathrm{C}}\right)$ of 300 Oe and a reduced magnetization $(\mathrm{Mr})$ value of 0.4 were observed for the magnetization cycle collected at low temperature (2.5 K, Figure S4B). The saturation magnetization $\left(\mathrm{M}_{\mathrm{S}}\right)$ at $300 \mathrm{~K}$ was $72 \mathrm{Am}^{2} / \mathrm{kg}$, and was only $20 \%$ lower than that of the bulk magnetite, ${ }^{39}$ indicating that the synthesized material was highly crystalline. The $\mathrm{Fe}_{3} \mathrm{O}_{4}$ nanoparticles were then stabilized by capping the surface with hydroxamic acid, ethyl 12-(hydroxyamino)-12oxododecanoate 1 (Figure 1).

Dynamic light scattering showed that $\mathrm{Fe}_{3} \mathrm{O}_{4}-1$ had a uniform size distribution, an average diameter of $25.6 \pm 0.3 \mathrm{~nm}$, and a polydispersity index of $0.19 \pm 0.01$ (Figure S5). Infrared analysis was also performed to confirm ligand attachment (Figure S6). For synthesis of poly(D,L-lactide-co-glycolide)(PLGA)- $b$-PEG-COOH, the carboxyl-capped PLGA-COOH was activated with N-hydroxysuccinimide using dicyclohexylcarbodiimide coupling chemistry and then conjugated to the carboxylic aminodifunctional PEG in chloroform and in the presence of diisopropylethylamine. ${ }^{40-42}$ The lipophilic $\mathrm{Fe}_{3} \mathrm{O}_{4}-1$ was then entrapped into the PLGA- $b$-PEG-COOH using the nanoprecipitation technique ${ }^{40-43}$ as reported in Figure 1, giving $\mathrm{Fe}_{3} \mathrm{O}_{4}-1-\mathrm{PNPs}$. For nanoprecipitation, we selected acetone as the solvent and used an acetone to water ratio of $1 / 10$ and a polymer concentration of $2.5 \mathrm{mg} / \mathrm{mL}$ in acetone; after purification and concentration, we obtained $40 \mathrm{~mL}$ of a $10.0 \mathrm{mg} / \mathrm{mL}$ colloidal suspension in water relative to the iron oxide, evaluated by inductively coupled plasma mass spectrometry. The mean particle size and mean polydispersity index for $\mathrm{Fe}_{3} \mathrm{O}_{4}$-1-PNPs was determined by dynamic light scattering, and found to be $60.5 \pm 0.9 \mathrm{~nm}$ and $0.15 \pm 0.02$, respectively, indicating a narrow size distribution (Figure S7). Transmission (Figure 2A) and scanning (Figure S8) electron micrographs for $\mathrm{Fe}_{3} \mathrm{O}_{4}$-1-PNPs showed clusters of small numbers of inorganic particles homogeneously dispersed in the polymeric matrix with an average diameter of $22.1 \pm 3.8 \mathrm{~nm}$.

Next, we chemically linked the anti-hEGFR to the outer surface $(\mathrm{COOH})$ of the PNPs using typical 1-ethyl3-(3-dimethylaminopropyl) carbodiimide chemistry. We added 1-ethyl-3-(3-dimethylaminopropyl) carbodiimide and N-hydroxysulfosuccinimide to $\mathrm{Fe}_{3} \mathrm{O}_{4}$-1-PNPs (diluted up to $2.0 \mathrm{mg} / \mathrm{mL}$ of inorganic phase) in phosphate-buffered solution, then added a solution of anti-hEGFR (10 $\mathrm{mg}$ in phosphate buffer at a concentration of $2.5 \mathrm{mg} / \mathrm{mL}$ ). The reaction was carried out at room temperature, and after purification and concentration, we obtained $10 \mathrm{~mL}$ of a $2.6 \mathrm{mg} / \mathrm{mL}$ suspension of $\mathrm{Fe}_{3} \mathrm{O}_{4}-1$-PNPs-hEGFR (Figure 1) expressed in terms of iron oxide, with a process yield of about $78 \%$ in terms of inorganic phase. The iron content was determined by inductively coupled plasma mass spectrometry. The percent
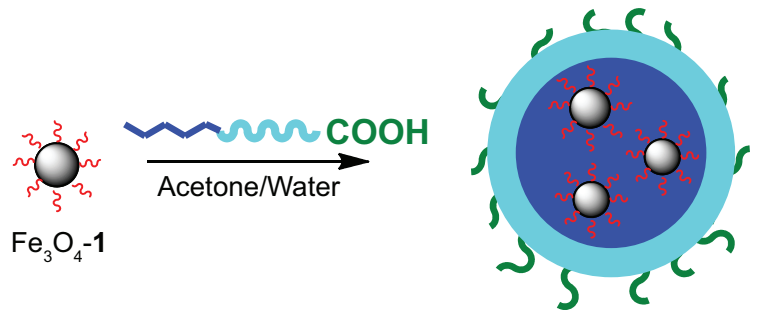

$\mathrm{Fe}_{3} \mathrm{O}_{4}-1-\mathrm{PNPS}$

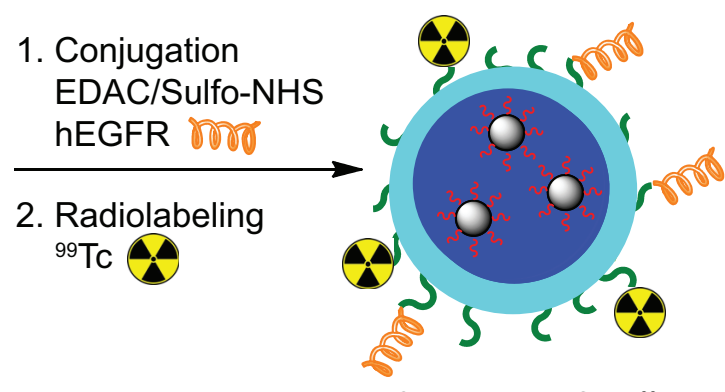

$\mathrm{Fe}_{3} \mathrm{O}_{4}-1-P N P s-h E G F R-{ }^{99} \mathrm{Tc}$

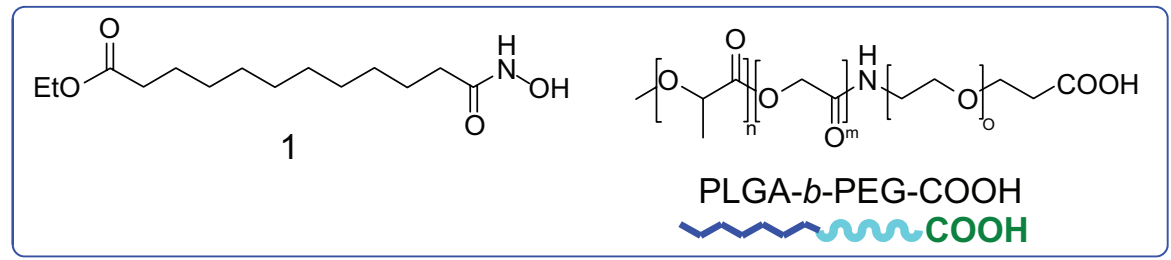

Figure I Schematic representation of all the major steps for synthesis of $\mathrm{Fe}_{3} \mathrm{O}_{4}$-I-PNPs-hEGFR-99mTc. Structures of the ligand ethyl I2-(hydroxyamino)- I2-oxododecanoate I and PLGA-b-PEG-COOH copolymer are reported in the blue frame.

Abbreviations: PLGA, poly(D,L-lactide-co-glycolide); hEGFR, human epidermal growth factor receptor; PNPs, polymeric nanoparticles; PEG, poly(ethylene glycol). 
A

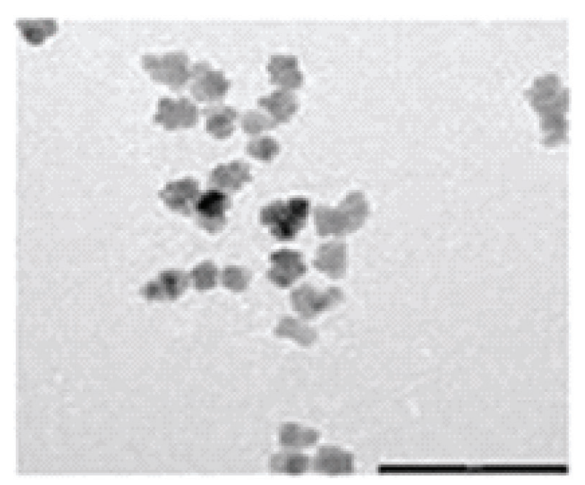

B

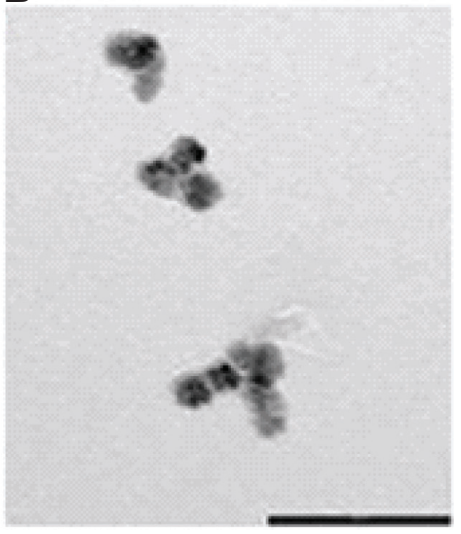

Figure 2 Transmission electron micrographs of $(\mathbf{A}) \mathrm{Fe}_{3} \mathrm{O}_{4}-\mathrm{I}-\mathrm{PNPs}$ (scale bar, $100 \mathrm{~nm}$ ) and (B) $\mathrm{Fe}_{3} \mathrm{O}_{4}-\mathrm{I}-\mathrm{PNP}$-hEGFR (bar scale, I00 nm). In both the images, aggregates of iron oxide nanoparticles into spherical-shaped larger carriers (PNPs) can be seen.

Abbreviations: hEGFR, human epidermal growth factor receptor; PNPs, polymeric nanoparticles.

weight of PNPs was determined by differential scanning calorimetry-thermogravimetric analysis. The organic content was found to be $42 \%$ of the total sample weight, indicating a concentration of $1.8 \mathrm{mg} / \mathrm{mL}$ in our solution. Thus, the encapsulation efficiency of iron oxide in the particles was estimated to be $1.38 \mathrm{mg} / \mathrm{mg}$. Mean particle size was $77.8 \pm 2.1 \mathrm{~nm}$ and mean polydispersity index was $0.12 \pm 0.01$ by dynamic light scattering. The mean zeta potential of $-34.5 \pm 0.3 \mathrm{mV}$ further confirmed their stability (Figure S9). The transmission electron micrographs confirmed the results of the dynamic light scattering investigations, showing no alteration of the inner morphological structure of $\mathrm{Fe}_{3} \mathrm{O}_{4}$-1-PNP-hEGFR (Figure 2B). The magnetic properties of the inorganic core were well preserved after the entrapment procedure, for both $\mathrm{Fe}_{3} \mathrm{O}_{4}$-1-PNPs and $\mathrm{Fe}_{3} \mathrm{O}_{4}$-1-PNPs-hEGFR (Figure $\mathrm{S} 10)$. In particular, $\mathrm{H}_{\mathrm{C}}$ and $\mathrm{Mr}$ were retained, with a weak reduction of $\mathrm{M}_{\mathrm{S}}\left(68 \mathrm{Am}^{2} / \mathrm{kg}\right.$ at $\left.300 \mathrm{~K}\right)$ that can be ascribed to the accuracy in the measurements of the magnetic material concentration.

Ultraviolet-visible spectroscopic analysis was carried out to quantify the monoclonal antibody using the bicinchoninic acid assay in three samples: $\mathrm{Fe}_{3} \mathrm{O}_{4}$-1-PNPs-hEGFR; $\mathrm{Fe}_{3} \mathrm{O}_{4}-1-\mathrm{PNPs}$ without the grafted monoclonal antibody in order to evaluate the signal ascribed to analytical interference; and wash waters collected during the purification step. The results (Figure S13) show that the concentration of monoclonal antibody in the wash waters was below the detection limit and can therefore be considered negligible, whereas the monoclonal antibodies were attached to the hybrid nanoparticles at a concentration of $551 \mu \mathrm{g} / \mathrm{mL}$, giving a weight ratio of monoclonal antibody to $\mathrm{Fe}_{3} \mathrm{O}_{4}$ of 0.21 . The method used allows for the recovery of $>99 \%$ of the monoclonal antibody. The specific absorption rate evaluated for a dispersion of $\mathrm{Fe}_{3} \mathrm{O}_{4}-1$-PNPs-hEGFR was $264.5 \pm 3.0 \mathrm{~W} / \mathrm{g}_{\mathrm{Fe}}$; although some decrease in the intrinsic hyperthermic efficiency of the pure native inorganic nanoparticles was recorded $\left(372.4 \pm 3.6 \mathrm{~W} / \mathrm{g}_{\mathrm{Fe}}\right)$ due to encapsulation, it remains comparable with or even higher than the best values reported in literature so far, ${ }^{44}$ operating within the range of physiological tolerance. A similar alternating magnetic field excitation is expected when the nanosystems are intratumorally injected into mice. ${ }^{45}$ To assess the hyperthermia effect, we applied an alternating magnetic field of $\mathrm{H}_{0} \sim 25 \mathrm{kA} / \mathrm{m}$ at a frequency of $\mathrm{f}=173 \mathrm{kHz}$.

Radiolabeling of a hybrid $\mathrm{Fe}_{3} \mathrm{O}_{4}$-1-PNPs-hEGFR nanoformulation with ${ }^{99 \mathrm{~m}} \mathrm{Tc}$ was performed under mild conditions using $\mathrm{SnCl}_{2}$ as the reducing agent, as previously described ${ }^{46}$ Radiolabeled nanoparticles with and without hEGFR were produced in high yields $(>98 \%)$ and were relatively stable. Magnetic measurements of a $\mathrm{Fe}_{3} \mathrm{O}_{4}$-1-PNPshEGFR- ${ }^{99 \mathrm{~m}} \mathrm{Tc}$ sample showed that the radiolabeling procedure did not significantly affect the most important magnetic parameters (Figure S10). Our group had already performed stability studies of the final nanosystem under biological conditions before its use in vivo, which showed maintenance of its favorable properties after 24 hours of incubation in human serum. ${ }^{47}$ The radiolabeled $\mathrm{Fe}_{3} \mathrm{O}_{4}$-1-PNPs-hEGFR${ }^{99 \mathrm{~m}} \mathrm{Tc}$ nanosystem had previously been injected intravenously into one A431 tumor-bearing mouse ${ }^{48}$ and a typical image obtained at one hour post injection is shown in Figure 3. The maximum concentration was observed in the liver, which remained fairly constant over time, and a significant concentration was found in the spleen as well. Significant accumulation at the tumor site, located on the left shoulder, was clearly visible when compared with the corresponding muscle tissue on right shoulder, and is attributed directly to the 


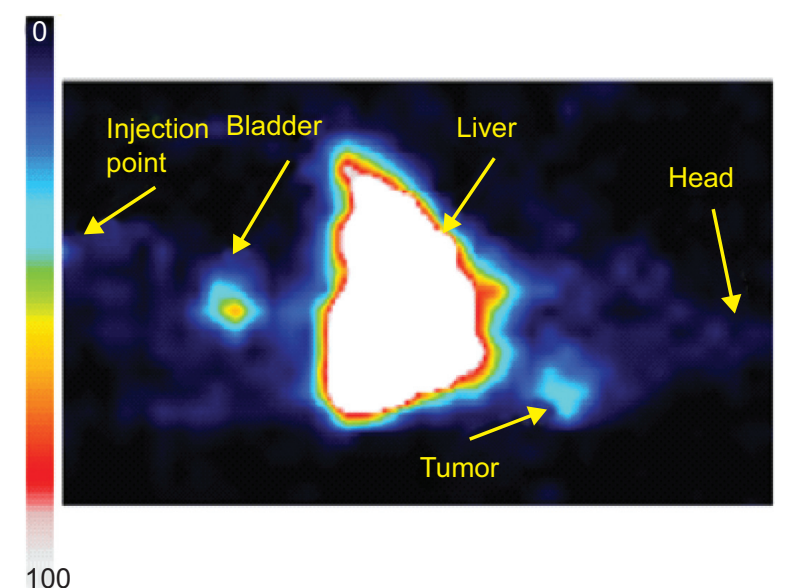

Figure 3 Scintigraphic image of hybrid radiolabeled $\mathrm{Fe}_{3} \mathrm{O}_{4}-\mathrm{I}-\mathrm{PNP}-\mathrm{hEGFR}-{ }^{99 \mathrm{~m}} \mathrm{Tc}$ in an A43I tumor-bearing SCID mouse model. The tumor site is clearly visible, indicating accumulation of the nanosystems.

Abbreviations: hEGFR, human epidermal growth factor receptor; PNP, polymeric nanoparticles; SCID, severe combined immunodeficiency.

EGFR antibody-receptor interaction. Scintigraphic imaging after administration of the $\mathrm{Fe}_{3} \mathrm{O}_{4}-1$-PNPs- ${ }^{99 m} \mathrm{Tc}$ nanocarrier (without hEGFR) in healthy and tumor-bearing mice did not show any uptake. The concentration seen in the liver and adjacent spleen was expected, since the nontargeted radiolabeled nanosystem has also been shown to concentrate in organs of the reticuloendothelial system when administrated in healthy mice. Finally, the concentration of nanoparticles in the bladder indicates a prolonged circulation time in blood.

Tumor growth following inoculation occurred in all six animals. The first group of two nontreated (control) animals had poor survival (13-14 days) and a tumor volume in the range of $200-400 \mathrm{~mm}^{3}$. The second group of two animals that had been treated with only $100 \mu \mathrm{L}$ of $\mathrm{Fe}_{3} \mathrm{O}_{4}$-1-PNPshEGFR on two consecutive days also had a short survival time (13 days), which was similar to that in the control group. However, survival time was markedly longer in the two mice

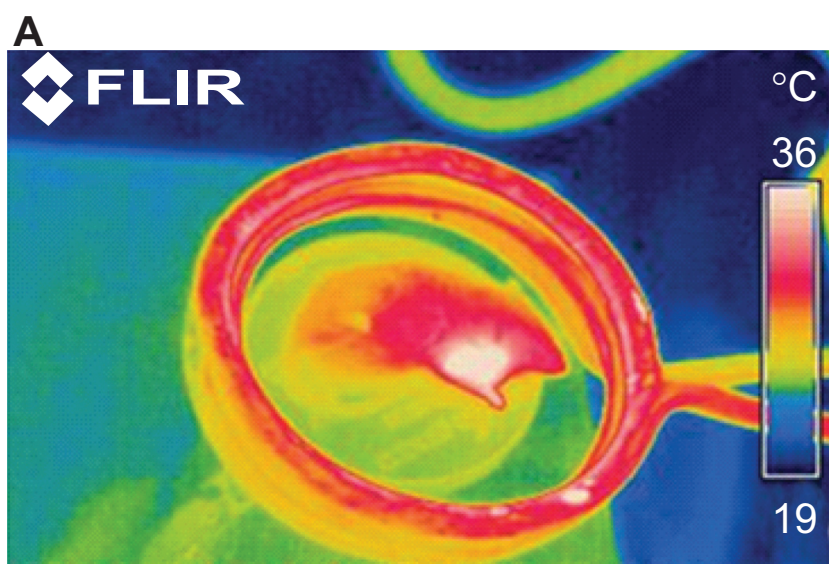

in the third group that received five intratumoral injections on days $16,17,18,19$, and 22 , with one mouse surviving up to day 19 and the second mouse surviving up to day 26. All mice were imaged with the near infrared camera from the beginning until the end of the hyperthermia session. A typical image of a mouse placed inside the coil during the hyperthermia session is shown in Figure 4 up to day 22, where the tumor region is shown as a white spot. Analysis of images from the near infrared camera shows a temperature increase of 5-6 degrees in the tumor region compared with that observed elsewhere in the animal's body and organs (Figure 4B). In all sessions, the temperature rise in the tumor area reached a plateau within the first 10-15 minutes after thermotherapy. An increase of $1^{\circ} \mathrm{C}-2^{\circ} \mathrm{C}$ was observed throughout the rest of the mouse body, mainly due to the small temperature increase in the coil which was transferred to the environment, but did not affect the conclusion drawn from the experiment.

Analysis of the images obtained during the hyperthermia sessions gave a series of curves showing a temperature increase in the tumor on days 16, 17, 18, 19, and 22 (marked as day 1, 2, 3, 4, and 7 from the first injection; Figure 5A). In all cases, the tumor temperature reached a plateau after 10-15 minutes of hyperthermia, and the maximum outer temperature increased from $28^{\circ} \mathrm{C}$ on day 1 to $37^{\circ} \mathrm{C}$ on day 7 . Figure $5 \mathrm{~B}$ shows the tumor volume in the second mouse of the third group. A substantial decrease in tumor size is shown, which correlates well with the increasing nanoparticle concentration and substantial temperature increase.

\section{Discussion}

In the determination of size of the magnetic nanoparticles $\mathrm{Fe}_{3} \mathrm{O}_{4}$ the minor discrepancies between the two techniques (X-ray diffraction and dynamic light scattering) have to be

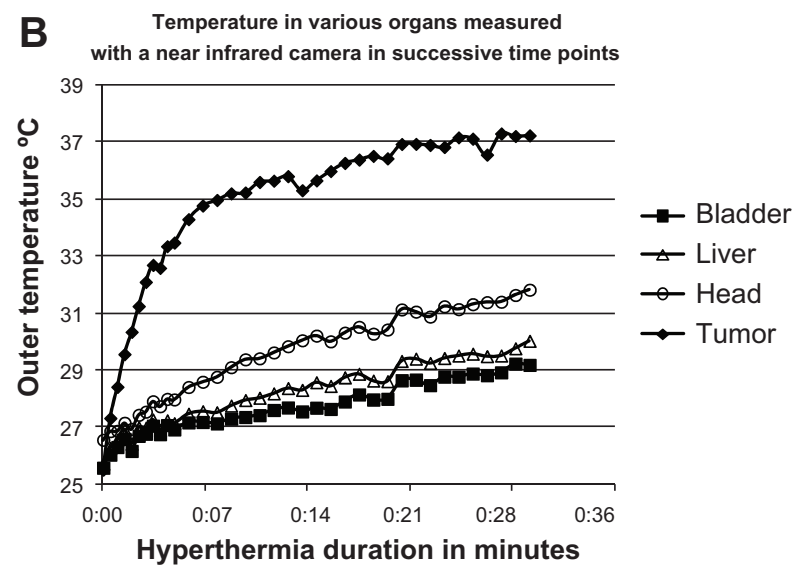

Figure 4 Monitoring of whole body temperature in a mouse placed inside the inductive coil of the hyperthermia system using a FLIR infrared camera at day 22. Notes: Increased outer temperature is evident in the tumor region $(\mathbf{A})$. Temperature increase in the tumor, head, liver, and mouse bladder during the hyperthermia session (B). ThermaCAMTM E300 (FLIR) (FLIR Systems Inc., Meer, Belgium). 
A

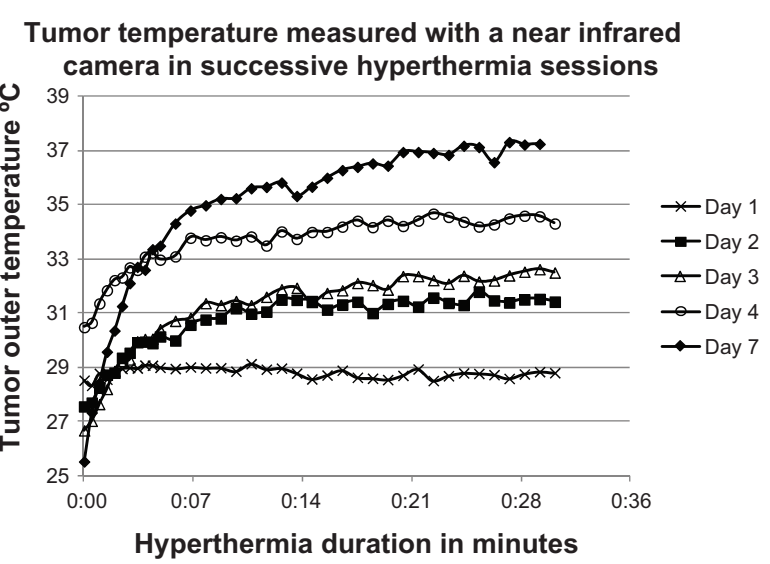

B

Tumor volume in $\mathrm{mm}^{3}$

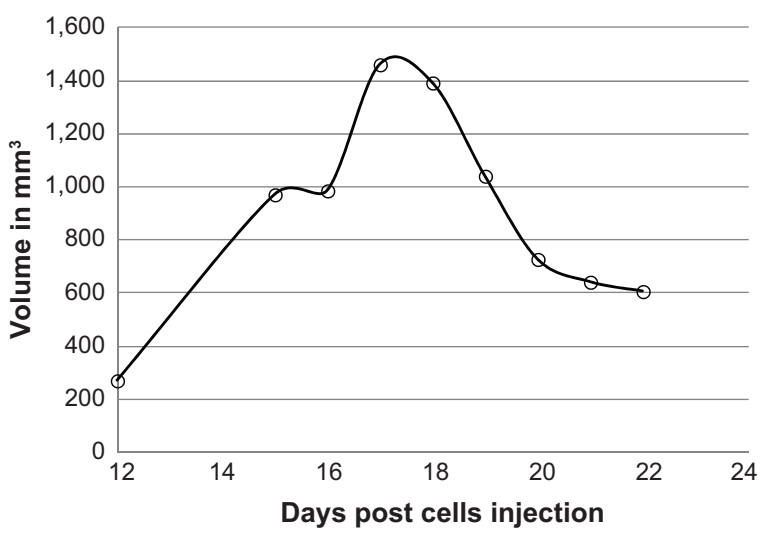

Figure $\mathbf{5}$ Temperature increase at the tumor region in the second mouse in the third group for all hyperthermia sessions (A). Tumor volume in the same mouse on day 12 through day 24 , showing a decrease in tumor volume (B).

ascribed not only to the analytical information provided by each one (the size of the coherent crystalline domain the first, the value of the hydrodynamic diameter including the solvation sphere the latter), but rather to the formation of polycrystalline "flower-like" particles during the synthetic process. Indeed, transmission electron microscopy of the inorganic core showed good agreement between the techniques, indicating the presence of assemblies of particles composed of smaller domains (Figure S3).

As far as magnetic properties are concerned, the blocking temperature $\left(\mathrm{T}_{\mathrm{B}}\right.$, commonly identified as the temperature at which the zero-field-cooled curve reaches its maximum) could not be clearly identified due to the abrupt increase around $200 \mathrm{~K}$ subsequent to the thawing of the diethylene glycol solution (Figure S4A), but can be located in the 150-200 K range, ie, well below room temperature. At the temperatures of interest for medical applications, the system is thus expected to be in the superparamagnetic region.

To entrap the magnetic core into the PLGA-PEG polymer suitable for a lipophilic nanoparticles is needed. Therefore to homogeneously disperse $\mathrm{Fe}_{3} \mathrm{O}_{4}$ in acetone the use of hydroxamic functionality has been developed by us $^{49,50}$ as a suitable alternative to the well known method that uses carboxylic acid to coat magnetic NPs. ${ }^{51}$ The X-ray diffraction pattern for the lipophilic $\mathrm{Fe}_{3} \mathrm{O}_{4}-1$ confirmed that the original crystallite size was preserved during functionalization, as previously reported for cobalt ferrite nanoparticles. ${ }^{42}$ In addition, the main magnetic characteristics of the particles (ie, $\mathrm{Mr}, \mathrm{M}_{\mathrm{S}}$, and $\mathrm{H}_{\mathrm{C}}$ ) were found to be unaffected by the superficial coating, suggesting that the chemical state of the surface ions was not significantly modified (Figure S10).
In order to entrap the lipophilic magnetic nanoparticles, our polymer of choice was PLGA- $b$-PEG-COOH. This polymer self-assembles to form targetable PNPs (due to $\mathrm{COOH}$ ), consisting of a hydrophobic PLGA core and a hydrophilic PEG corona-like shell. ${ }^{52,53}$ After polymeric entrapment of $\mathrm{Fe}_{3} \mathrm{O}_{4}-1$ in $\mathrm{Fe}_{3} \mathrm{O}_{4}-1-\mathrm{PNPs}$, the average diameter of each magnetite core was evaluated by statistical analysis and found to be in good agreement with the uncoated $\mathrm{Fe}_{3} \mathrm{O}_{4}$, while the average diameter of each hybrid assembly was compatible with that found by dynamic light scattering.

A431 epidermoid carcinoma cells overexpress EGFR and can be used as a positive control for in vivo experiments with hEGFR-targeted nanoparticles. Moreover, EGFR is found overexpressed in human malignancies, including skin cancers. ${ }^{54}$ The functional ability of the anti-EGFR antibody to recognize EGFR expressed in the membranes of this cell line was checked by flow cytometry. To this end, A431 cells and MDA-MB-231 cells expressing EGFR were labeled with the monoclonal antibody. A Jurkat cell line was used as a negative expression control. An unrelated mouse-immunoglobulin G2a antibody was used as a negative control to fix the position of the cursor. As expected, the Jurkat cells were not labeled by the anti-EGFR antibody, whereas the MDAMB-231 cells, and in particular the A431 cells, showed a high labeling index (Figure S11).

With our final target being an in vivo proof-of-concept in a skin cancer model, we produced and purified an antihEGFR monoclonal antibody from an HB-9764 hybridoma cell line acquired from the American Type Culture Collection (see Materials and methods). After chemical conjugation of the monoclonal antibody in the outer shell of the $\mathrm{Fe}_{3} \mathrm{O}_{4}$ 1-PNPs, the resulting $\mathrm{Fe}_{3} \mathrm{O}_{4}$-1-PNP-hEGFR showed good 
dynamic light scattering and a low polydispersity index, so we were able to exclude the possibility of any aggregation phenomenon with regard to the hybrid particles inside the suspension.

The selected field parameters were low enough to allow their product to undergo the physiological tolerance limit as reported, ${ }^{55-57}$ ie, $\mathrm{H}_{0} \mathrm{f}<5 x^{*} 10^{9} \mathrm{~A} \mathrm{~Hz} \mathrm{~m}$. At the same time the selected field parameters are suitable to excite the magnetic cores and produce a significant heating effect.

$\mathrm{Fe}_{3} \mathrm{O}_{4}-1-\mathrm{PNP}-\mathrm{hEGFR}$ was used to treat epidermoid cancer in an A431 tumor-bearing mouse model. It should be noted that A431 cells showed very aggressive tumor growth when implanted in SCID mice, and similarly aggressive A431 tumor growth was observed in another study using BALB/c nude mice provided by Charles River Laboratories International Inc. ${ }^{55}$ Considering such fast and aggressive tumor growth, the optimal time to start local treatment may be at an earlier stage, since this seemed to be very critical for survival of the animals. Although the therapeutic results obtained in this model were derived from a small sample, they are reasonably indicative and suggest that the proposed system would be more efficient in a less aggressive tumor model.

The radiolabeling steps required further dilution of the nanoparticles, so we used nonradiolabeled nanoparticles injected directly into the tumor in order to maximize their concentration and improve the possibility of being able to administer hyperthermia. A similar approach has been used by other research groups. ${ }^{22,58,59}$ Apart from tumor volume that was almost daily measured with a caliper, changes in mouse weight were also recorded and no toxicity was observed since the mouse weight did not demonstrate any decrease. This is in accordance with similar protocols that require use of milligram amounts of magnetic nanoparticles and a long hyperthermia exposure time of 30 minutes. ${ }^{56,57}$ Figure 5A shows that the first injections did not result in a significant temperature increase during hyperthermia. However, as the concentration of nanoparticles increased, a substantial increase in temperature was observed, with the outer temperature exceeding $37^{\circ} \mathrm{C}$ on day 22 ( 7 days since the first injection). Taking into account the fact that a near infrared camera measures only the outer temperature, it is expected that the measured external temperature is lower than the internal, due to absorbance from tissue, as well as other factors which are discussed at the end of this section. Since this is one of the first studies to use a near infrared camera for measurement of a temperature increase in vivo, we report here some parameters that need to be considered when interpreting such measurements. It is important to take into account that a near infrared camera measures only the external temperature, which is strongly affected by tissue absorbance. In addition, deviation in temperatures recorded with the infrared camera from expected values can be attributed to several factors, including: the distance between the infrared camera and the mouse positioned in the coil; temperature loss due to heat exchange with the environment; and the depth of the seated tumor. For these reasons, although the maximum temperature measured did not exceed $37^{\circ} \mathrm{C}$, a hyperthermic effect was evident in the decreased tumor size and increased survival time. In this study, we directly injected tumors but our ultimate goal is tumor targeting. However, when intravenous injection is considered, the total amount of nanoparticles that are introduced in the mouse can be several orders of magnitude lower than the concentration required to achieve a hyperthermic effect. This is due to the limited quantities (100-200 $\mu \mathrm{L})$ that can be injected in vivo as well as the further dilution on the entire tumor volume, which can be of several milliliters. Targeting properties should be also taken into account. In this study, the nanoparticle $\left(\mathrm{Fe}_{3} \mathrm{O}_{4}\right)$ concentration that was sufficient to have a hyperthermic effect was $4.52 \mathrm{mg} / \mathrm{mL}$. However, if only $100 \mu \mathrm{L}$ are intravenously injected in a mouse, and if tumor targeting is $\sim 10 \%$, then only a very low portion of the initial nanoparticles will be distributed on the tumor. In this case the concentration on the tumor will not be sufficient to raise a hyperthermia effect. For this reason, we elected to inject the tumor directly to determine if the proposed system can have a hyperthermic effect. Improvement of tumor targeting is one of the parameters that should be optimized in order to achieve hyperthermia with intravenous injection. A second option would be to exploit nanoparticles that can lead to a significantly higher temperature increase, so that a hyperthermic effect is feasible even at low concentrations in tumor tissue. Finally, improvements in the hyperthermia equipment used, in terms of coil dimensions and size and the range of frequencies and magnetic fields, could be exploited.

\section{Conclusion}

In summary, we have reported the synthesis of $\mathrm{Fe}_{3} \mathrm{O}_{4}-1-\mathrm{PNP}-$ hEGFR as a novel theranostic agent. ${ }^{99 \mathrm{~m}} \mathrm{Tc}$-radiolabeling of the nanocarrier allowed in vivo biodistribution in A431 tumorbearing mice and detection of the antibody-receptor interaction, while the entrapped magnetic nanoparticles allowed proof of concept evaluation of the hyperthermic efficacy on tumor size reduction derived by the use of our nanocarrier. Our findings indicate the potential of this novel theranostic agent for hyperthermic treatment of cancer, and extensive optimizations are currently undergoing. 


\section{Acknowledgments}

The authors acknowledge the scientific personnel of the Radiochemical Studies Laboratory, INRSTES (Institute of Nuclear \& Radiological Sciences \& Technology, Energy \& Safety), and National Center For Scientific Research Demokritos. They are particularly grateful to Dr Penelope Bouziotis for her constructive discussions and to Stavros Xanthopoulos for his valuable technical assistance. This work was partly supported with funds from the Nanother EU-FP7 project (CP-IP 213631-2). Authors CI and CS would also like to acknowledge Italian MIUR for financial support through project FIRB “RINAME” (RBAP114AMK).

\section{Disclosure}

The authors report no conflicts of interest in this work.

\section{References}

1. Schmidt G, editor. Nanoparticles. From Theory to Application. Weinheim, Germany: Wiley-VCH Verlag GmbH \& Co. KGaA; 2004.

2. Feldheim DL, Foss CA. Metal Nanoparticles. Synthesis, Characterisation, and Application. New York, NY, USA: Dekker; 2002.

3. Vollath D, editor. Nanomaterials. Weinheim, Germany: Wiley-VCH Verlag GmbH \& Co. KGaA; 2008.

4. Cademartiri L, Ozin GA. In: Lehn JM, editor. Concepts of Nanochemistry. Weinheim, Germany: Wiley-VCH Verlag GmbH \& Co. KGaA; 2009.

5. Gao I. Biofunctionalization of nanomaterials. In: Challa SS, Kumar R, editors. Nanotechnologies for the Life Sciences. Weinheim, Germany: Wiley-VCH Verlag GmbH \& Co. KGaA; 2006.

6. Hayashi K, Nakamura M, Sakamoto W, et al. Superparamagnetic nanoparticle clusters for cancer theranostics combining magnetic resonance imaging and hyperthermia treatment. Theranostics. 2013;3: 366-376.

7. Lartigue L, Hugounenq P, Alloyeau D, et al. Cooperative organization in iron oxide multi-core nanoparticles potentiates their efficiency as heating mediators and MRI contrast agents. ACS Nano. 2012;6:10935-10949.

8. Thomas LA, Dekker L, Kallumadil M, et al. Carboxylic acid-stabilised iron oxide nanoparticles for use in magnetic hyperthermia. $J$ Mater Chem. 2009;19:6529-6535.

9. Kaddi CD, Phan JH, Wang MD. Computational nanomedicine: modeling of nanoparticle-mediated hyperthermal cancer therapy. Nanomedicine. 2013;8:1323-1333.

10. Dürr S, Janko C, Lyer S, et al. Magnetic nanoparticles for cancer therapy. Nanotechnology Reviews. 2013;2:395-409.

11. Kumar CS, Mohammad F. Magnetic nanomaterials for hyperthermiabased therapy and controlled drug delivery. Adv Drug Deliv Rev. 2011;63:789-808.

12. Peer D, Karp JM, Hong S, Farokhzad OC, Margalit R, Langer R. Nanocarriers as an emerging platform for cancer therapy. Nat Nanotechnol. 2007;2:751-759.

13. Huang Y, He S, Cao W, Cai K, Liang XJ. Biomedical nanomaterials for imaging-guided cancer therapy. Nanoscale. 2012;4: 6135-6149.

14. Chen H, Li S, Li B, et al. Folate-modified gold nanoclusters as nearinfrared fluorescent probes for tumor imaging and therapy. Nanoscale. 2012;4:6050-6064.

15. Yang J, Lee CH, Ko HJ. Multifunctional magneto-polymeric nanohybrids for targeted detection and synergistic therapeutic effects on breast cancer. Angew Chem Int Ed. 2007;46:8836-8839.
16. Ahmed N, Fessi H, Elaissari A. Nanoparticles for cancer from diagnosis to theranostics. Drug Deliv Today. 2012;17:928-934.

17. Thiesen B, Jordan A. Clinical applications of magnetic nanoparticles for hyperthermia. Int J Hyperthermia. 2008;24:467-474.

18. Maier-Hauff K, Ulrich F, Nestler D, et al. Efficacy and safety of intratumoral thermotherapy using magnetic iron-oxide nanoparticles combined with external beam radiotherapy in patients with recurrent glioblastomamultiforme. J Neurooncol. 2011;103:317-324.

19. Prasad K, Rathinasamy K, Panda D, et al. Mechanism of cell death induced by magnetic hyperthermia with nanoparticles of $\gamma-\mathrm{Mn}_{\mathrm{x}} \mathrm{Fe}_{2-\mathrm{x}} \mathrm{O}_{3}$ synthesized by a single step process. J Mater Chem. 2007; 17:5042-5051.

20. Jung JT, Nah H, Lee JH, Moon SH, Kim MG, Cheon J. Critical enhancements of MRI contrast and hyperthermic effects by dopant-controlled magnetic nanoparticles. Angew Chem Int Ed. 2009;48:1234-1238.

21. Lee JH, Jong JT, Choi JS, et al. Exchange-coupled magnetic nanoparticles for efficient heat induction. Nat Nanotechnol. 2011;6:418-422.

22. Yoo D, Jeong H, Preihs C, et al. Double-effector nanoparticles: a synergistic approach to apoptotic hyperthermia. Angew Chem Int Ed Engl. 2012;51:12482-12485.

23. Ito A, Kuga Y, Honda H, et al. Magnetite nanoparticle-loaded antiHER2 immunoliposomes for combination of antibody therapy with hyperthermia. Cancer Lett. 2004;212:167-175.

24. Macková H, Horák D, Trachtová Š, Rittich B, Španová A. The use of magnetic poly(N-isopropylacrylamide) microspheres for separation of DNA from probiotic dairy products. Journal of Colloid Science and Biotechnology. 2012;1:235-240.

25. Rahman MM, Elaissari A. Multi-stimuli responsive magnetic core-shell particles: synthesis, characterization and specific RNA recognition. Journal of Colloid Science and Biotechnology. 2012;1: $3-15$.

26. Medeiros SF, Santos AM, Fessi H, Elaissari A. Thermally-sensitive and magnetic poly(n-vinylcaprolactam)-based nanogels by inverse miniemulsion polymerization. Journal of Colloid Science and Biotechnology. 2012;1:99-112.

27. Shen JM, Yin T, Tian XZ, Gao FY, Xu S. Surface chargeswitchable polymeric magnetic nanoparticles for the controlled release of anticancer drug. ACS Appl Mater Interfaces. 2013;5: 7014-7024.

28. Shen JM, Gao FY, Yin T, et al. cRGD-functionalized polymeric magnetic nanoparticles as a dual-drug delivery system for safe targeted cancer therapy. Pharmacol Res. 2013;70:102-115.

29. Shen JM, Guan XM, Liu XY, Lan JF, Cheng T, Zhang HX. Luminescent/magnetic hybrid nanoparticles with folate-conjugated peptide composites for tumor-targeted drug delivery. Bioconjug Chem. 2012;23:1010-1021.

30. Machulla HJ, Uludag K, Cherry SR, et al. Simultaneous PET-MRI: a new approach for functional and morphological imaging. Nat Med. 2008;14:459-465.

31. Meier D, Wagenaar DJ, Chen S, Xu J, Yu J, Tsui BM. A SPECT camera for combined MRI and SPECT for small animals. Nucl Instrum Methods Phys Res A. 2011;652:731-734.

32. Bouziotis P, Psimadas D, Tsotakos T, Stamopoulos D, Tsoukalas C. Radiolabeled iron oxide nanoparticles as dual-modality SPECT/MRI and PET/MRI agents. Curr Top Med Chem. 2012;12: 2694-2702.

33. Comes Franchini M, Baldi G, Bonacchi D, et al. Bovine serum albumin-based magnetic nanocarrier for MRI diagnosis and hyperthermic therapy: a potential theranostic approach against cancer. Small. 2010;6:366-370.

34. Misri R, Meier D, Yung AC, Kozlowski P, Häfeli UO. Development and evaluation of a dual-modality (MRI/SPECT) molecular imaging bioprobe. Nanomedicine. 2012;8:1007-1016.

35. Knop K, Hoogenboom R, Fischer D, Schubert US. Poly(ethylene glycol) in drug delivery: pros and cons as well as potential alternatives. Chem Rev. 2010;49:6288-6308. 
36. Loudos G, Majewski S, Wojcik R, Varvarigou A. Performance evaluation of a dedicated camera suitable for dynamic radiopharmaceuticals evaluation in small animals. IEEE Trans Nucl Sci. 2007:54:3-9.

37. Juarranz A, Jaén P, Sanz-Rodríguez F, Cuevas J, González S. Photodynamic therapy of cancer. Basic principles and applications. Clin Transl Oncol. 2008;10:148-154.

38. Baldi G, Bonacchi D, Innocenti C, et al. Cobalt-ferrite nanoparticles: the control of the average size and surface state and their effects on magnetic properties. J Magn Magn Mater. 2007;311:10-16.

39. Hunt CP, Moskowitz BM, Banerjee SK. Magnetic properties of rocks and minerals. In: Ahrens TJ, editor. Rock Physics and Phase Relations: A Handbook of Physical Constants. Washington, DC, USA: American Geophysical Union; 1995.

40. Ai H, Flask C, Weinberg B, et al. Magnetite-loaded polymeric micelles as ultrasensitive magnetic-resonance probes. Adv Mater. 2005; 17:1949-1952.

41. Baldi G, Bonacchi D, Innocenti F. PCT Int. Appl. 2008, 71pp. CODEN: PIXXD2 WO 2008074804 A2 20080626.

42. Baldi G, Bonacchi D, Comes Franchini M, et al. Synthesis and coating of cobalt ferrite nanoparticles: a first step toward the obtainment of new magnetic nanocarriers. Langmuir. 2007;7:4026-4028.

43. Sun $\mathrm{S}$, Zeng $\mathrm{H}$, Robinson $\mathrm{DB}$, et al. Monodisperse $\mathrm{MFe}_{2} \mathrm{O}_{4}(\mathrm{M}=\mathrm{Fe}$, Co, Mn) nanoparticles. J Am Chem Soc. 2004;126:273-279.

44. Gref R, Minamitake Y, Peracchia MT, Trubetskoy V, Torchilin V, Langer R. Biodegradable long-circulating polymeric nanospheres. Science. 1994;263:1600-1603

45. Hergt R, Hiergeist RR, Zeisberger M, et al. Enhancement of AC-losses of magnetic nanoparticles for heating applications. J Magn Magn Mater. 2004;280:358-368.

46. Psimadas D, Baldi G, Ravagli C, et al. Preliminary evaluation of a ${ }^{99 \mathrm{~m}} \mathrm{Tc}$ labeled hybrid nanoparticle bearing a cobalt ferrite core: in vivo biodistribution. J Biomed Nanotechnol. 2012;8:575-585.

47. Psimadas D, Baldi G, Ravagli C. Comparison of the magnetic, radiolabeling, hyperthermic and biodistribution properties of hybrid nanoparticles bearing $\mathrm{CoFe}_{2} \mathrm{O}_{4}$ and $\mathrm{Fe}_{3} \mathrm{O}_{4}$ metal cores. Nanotechnology. 2014;25:25101-25110.
48. All animal protocols were performed in compliance with European legislation and have been approved by national authorities. Tumor size is measured according to the formula $0.5 \times$ length $\times$ width $^{2}$.

49. Comes Franchini M, Bonini BF, Camaggi CM, et al. Design and synthesis of novel pyrazoles for nanomedicine applications against malignant gliomas. Eur J Med Chem. 2010;45:2024-2033.

50. Locatelli E, Comes Franchini M. Biodegradable PLGA-b-PEG polymeric nanoparticles: synthesis, properties, and nanomedical applications as drug delivery system. J Nanopart Res. 2012;14:1316-1324.

51. Gu F, Zhang L, Teply BA, et al. Precise engineering of targeted nanoparticles by using self-assembled biointegrated block copolymers. Proc Natl Acad Sci U S A. 2008;105:2586-2595.

52. Hergt R, Dutz S. Magnetic particle hyperthermia - biophysical limitations of a visionary tumour therapy. J Magn Magn Mater. 2007;311:187-192.

53. Derfus AM, Maltzahn GV, Harris TJ, et al. Remotely triggered release from magnetic nanoparticles. Adv Mater. 2007;19:3932-3936.

54. Yarden Y, Sliwkowski MX. Untangling the ErbB signalling network. Nat Rev Mol Cell Biol. 2001;2:127-137.

55. Bleeker WK, Lammerts van Bueren JJ, van Ojik HH, et al. Dual mode of action of a human anti-epidermal growth factor receptor monoclonal antibody for cancer therapy. J Immunol. 2004;173:4699-4707.

56. Zhao Q, Wang L, Cheng R, et al. Magnetic nanoparticle-based hyperthermia for head and neck cancer in mouse models. Theranostics. 2012;2:113-121.

57. Jordan A, Scholz R, Maier-Hauff K, et al. The effect of thermotherapy using magnetic nanoparticles on rat malignant glioma. J Neurooncol. 2006;78:7-14

58. Elsherbini AA, Saber M, Aggag M, El-Shahawy A, Shokier HA. Magnetic nanoparticle-induced hyperthermia treatment under magnetic resonance imaging. Magn Reson Imaging. 2011;29:272-280.

59. Tanaka K, Ito A, Kobayashi K, et al. Intratumoral injection of immature dendritic cells enhances antitumor effect of hyperthermia using magnetic nanoparticles. Int J Cancer. 2005;116:624-633. 


\section{Supplementary information Synthesis of ethyl-12-hydroxydodecanoate}

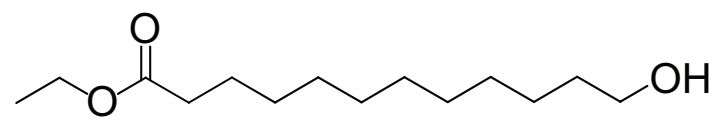

Acetyl chloride $(1.2 \mathrm{~mL}, 0.0168 \mathrm{~mol})$ was added to a stirred suspension of 12-hydroxydodecanoic acid (63.50 g, $0.293 \mathrm{~mol})$ in ethanol $(250 \mathrm{~mL})$ under nitrogen. The mixture was heated to $80^{\circ} \mathrm{C}$ and left to react for 24 hours. The solvent was then removed under vacuum and the white solid product obtained (yield $>99 \%$ ) was used without further purification. ${ }^{1} \mathrm{H}-\mathrm{NMR}\left(300 \mathrm{MHz}, \mathrm{CDCl}_{3}\right.$ ): $\delta=4.09$ (q, $2 \mathrm{H}$, $\mathrm{CH}_{2}$ ), 3.59 (t, $2 \mathrm{H}, \mathrm{CH}_{2}$ ), 2.23 (t, $2 \mathrm{H}, \mathrm{CH}_{2}$ ), 1.58 (bs, 6H, $\left.\mathrm{CH}_{2}\right), 1.25$ (bs, $\left.15 \mathrm{H}, \mathrm{CH}_{2}+\mathrm{CH}_{3}\right) \cdot{ }^{13} \mathrm{C}-\mathrm{NMR}$ : $(300 \mathrm{MHz}$, $\left.\mathrm{CDCl}_{3}\right): \delta=174.023(\mathrm{C}=\mathrm{O}), 61.835\left(\mathrm{CH}_{2}\right), 60.170$ $\left(\mathrm{CH}_{2}\right), 34.035\left(\mathrm{CH}_{2}\right), 32.578\left(\mathrm{CH}_{2}\right), 29.560\left(\mathrm{CH}_{2}\right), 29.477$ $\left(\mathrm{CH}_{2}\right), 29.385\left(2 \mathrm{CH}_{2}\right), 29.210\left(\mathrm{CH}_{2}\right), 29.047\left(\mathrm{CH}_{2}\right), 25.583\left(\mathrm{CH}_{2}\right)$, $24.913\left(\mathrm{CH}_{2}\right)$, and $14.200\left(\mathrm{CH}_{3}\right)$. ESI-MS: $267[\mathrm{M}+\mathrm{Na}]^{+}$.

\section{Synthesis of 12-ethoxy-12- oxododecanoic acid}

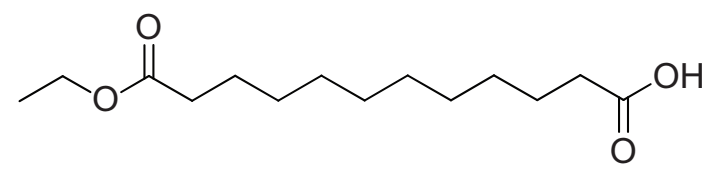

In a round bottom flask equipped with a $\mathrm{CaCl}_{2}$ trap, $1,600 \mathrm{~mL}$ of acetonitrile and periodic acid (140 g, $0.614 \mathrm{~mol})$ was introduced under nitrogen and the resulting suspension was kept under magnetic stirring for 40 minutes. Next, the system was cooled to $5^{\circ} \mathrm{C}$ with a thermostated bath, and a solution of ethyl 12-hydroxydodecanoate $(72.41 \mathrm{~g}, 0.285 \mathrm{~mol})$ and piridinium chlorochromate $(1.30 \mathrm{~g}, 0.00603 \mathrm{~mol})$ in $400 \mathrm{~mL}$ of acetonitrile was slowly added (addition time 50 minutes). The mixture was left to react for 24 hours at room temperature. The reaction was stopped by adding $1,500 \mathrm{~mL}$ of ethyl acetate, washed with water and brine, then with a solution of sodium hydrogen sulfite $(1 \times 1,000 \mathrm{~mL}, 2 \times 500 \mathrm{~mL})$ and again with water $(3 \times 500 \mathrm{~mL})$ and brine $(3 \times 750 \mathrm{~mL})$. The organic phase was anhydrificated with anhydrous sodium sulfate, filtered, and dried in vacuo to obtained the product as a white solid (68.52 g, $0.265 \mathrm{~mol}$, yield 93\%). ${ }^{1} \mathrm{H}-\mathrm{NMR}$ (300 MHz, $\mathrm{CDCl}_{3}$ ): $\delta=4.12$ (q, 2H, $\mathrm{CH}_{2}$ ), $2.37\left(\mathrm{t}, 2 \mathrm{H}, \mathrm{CH}_{2}\right), 2.29$ (t, $2 \mathrm{H}$, $\mathrm{CH}_{2}$ ), 1.61 (bs, $4 \mathrm{H}, \mathrm{CH}_{2}$ ), 1.26 (bs, $15 \mathrm{H}, \mathrm{CH}_{2}+\mathrm{CH}_{3}$ ). ${ }^{13} \mathrm{C}-\mathrm{NMR}$ : (150.92 MHz, $\left.\mathrm{CDCl}_{3}\right): \delta=180.046(\mathrm{C}=\mathrm{O}), 174.003(\mathrm{C}=\mathrm{O}), 60$ $.169\left(\mathrm{CH}_{2}\right), 34.342\left(\mathrm{CH}_{2}\right), 34.041\left(\mathrm{CH}_{2}\right), 29.441\left(\mathrm{CH}_{2}\right), 29.29$ $5\left(\mathrm{CH}_{2}\right), 29.156\left(2 \mathrm{CH}_{2}\right), 29.060\left(\mathrm{CH}_{2}\right), 28.987\left(\mathrm{CH}_{2}\right), 24.918$ $\left(\mathrm{CH}_{2}\right), 24.625\left(\mathrm{CH}_{2}\right), 14.198(\mathrm{CH} 3)$. ESI-MS: $281[\mathrm{M}+\mathrm{Na}]^{+}$.

\section{Synthesis of ethyl I 2-(hydroxyamino)- 12-oxododecanoate (I)}

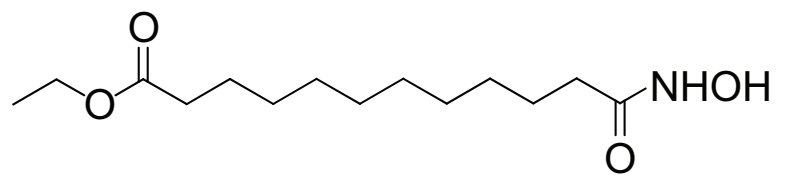

Thionyl chloride $(7.2 \mathrm{~mL}, 0.099 \mathrm{~mol})$ was slowly added (addition time 10 minutes) to a stirred solution of 12-ethoxy12-oxododecanoic acid (20.0 g, $0.077 \mathrm{~mol})$ in $190 \mathrm{~mL}$ of chloroform under nitrogen. The mixture was heated to reflux and left to react for 5 hours. The system was cooled to room temperature, and the solvent was removed under vacuum maintaining a nitrogen atmosphere. The resulting product was dissolved in dichloromethane $(190 \mathrm{~mL})$ and the obtained solution was cooled to $0^{\circ} \mathrm{C}$ using an ice bath. A solution of hydroxylamine hydrochloride $(7.14 \mathrm{~g}, 0.102 \mathrm{~mol})$ in pyridine $(71.4 \mathrm{~mL}, 0.88 \mathrm{~mol})$ was slowly added. The mixture was left to react for 12 hours at room temperature. The pyridinium salt was then eliminated by filtration and the solvent was evaporated under vacuum. The product was then purified by crystallization from methanol and the product was obtained as a white solid (19.1 g, $0.070 \mathrm{~mol}$, yield 91\%). Melting point was $68.3{ }^{\circ} \mathrm{C}-69.1{ }^{\circ} \mathrm{C} .{ }^{1} \mathrm{H}$ NMR $(300 \mathrm{MHz}$, DMSO-d6): $\delta=10.23$ (s, 1H, NH), $8.58(\mathrm{~s}, 1 \mathrm{H}, \mathrm{OH}), 3.99$ (q, $2 \mathrm{H}$, $\left.\mathrm{CH}_{2}\right), 2.21\left(\mathrm{t}, 2 \mathrm{H}, \mathrm{CH}_{2}\right), 1.84\left(\mathrm{t}, 2 \mathrm{H}, \mathrm{CH}_{2}\right), 1.43$ (bs, $\left.4 \mathrm{H}, \mathrm{CH}_{2}\right), 1.17$ (bs, $\left.15 \mathrm{H}, \mathrm{CH}_{2}+\mathrm{CH}_{3}\right) \cdot{ }^{13} \mathrm{C}-\mathrm{NMR}:(150.92 \mathrm{MHz}$, $\left.\mathrm{CDCl}_{3}\right): \delta=178.122(\mathrm{C}=\mathrm{O}), 174.012(\mathrm{C}=\mathrm{O}), 60.141$ $\left(\mathrm{CH}_{2}\right), 34.310\left(\mathrm{CH}_{2}\right), 34.039\left(\mathrm{CH}_{2}\right), 29.426\left(\mathrm{CH}_{2}\right), 29.278$ $\left(\mathrm{CH}_{2}\right), 29.141\left(2 \mathrm{CH}_{2}\right), 29.051\left(\mathrm{CH}_{2}\right), 28.975\left(\mathrm{CH}_{2}\right)$, $24.916\left(\mathrm{CH}_{2}\right), 24.611\left(\mathrm{CH}_{2}\right), 14.193\left(\mathrm{CH}_{3}\right)$. ESI-MS: $296[\mathrm{M}+\mathrm{Na}]^{+}$.

\section{Synthesis of PLGA-b-PEG-COOH}

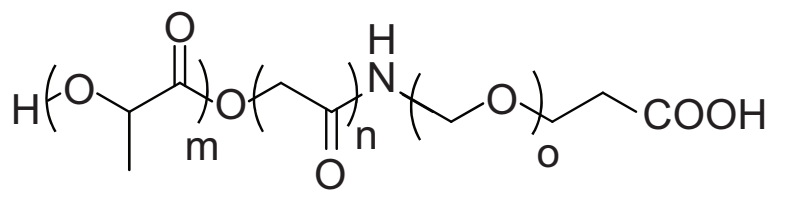

In the first step of the synthesis, poly(D,L-lactidecoglycolide) (PLGA)-COOH, $43 \mathrm{kDa},(1 \mathrm{~g}, 0.0232 \mathrm{mmol})$ and $N$-hydroxysuccinimide(NHS, $2.7 \mathrm{mg}, 0.0235 \mathrm{mmol}$ ) were dissolved in dichloromethane $(15 \mathrm{~mL})$. After cooling at $0^{\circ} \mathrm{C}$, $N, N^{\prime}$-dicyclohexylcarbodiimide $(7.27 \mathrm{mg}, 0.0352 \mathrm{mmol})$ was added and the mixture was left to warm up at room temperature and react for 24 hours. Next, dicyclohexylurea was removed by filtration and PLGA-NHS was precipitated with cold ethyl ether $(20 \mathrm{~mL})$ and repeatedly washed with the same solvent $(3 \times 10 \mathrm{~mL})$. After drying, the resulting white 
solid of PLGA-NHS (0.98 g) was collected and used in the next step without further purification.

In the second step of the synthesis, PLGA-NHS $(0.98 \mathrm{~g}$, $0.0227 \mathrm{mmol}$ ) was dissolved in chloroform $(20 \mathrm{~mL})$ followed by addition of $\mathrm{NH}_{2}$-PEG-COOH $(68 \mathrm{mg}, 0.0227 \mathrm{mmol})$ and $N, N$-diisopropylethylamine $(12 \mu \mathrm{L}, 0.0691 \mathrm{mmol})$. After 24 hours at room temperature, the copolymer was precipitated with cold diethyl ether $(30 \mathrm{~mL})$ and washed with the same solvent $(3 \times 10 \mathrm{~mL})$ and cold water $(3 \times 20 \mathrm{~mL})$ to remove unreacted $\mathrm{NH}_{2}$-PEG-COOH. The resulting white solid of PLGA- $b$-PEG-COOH (0.99 g, 0.0215 mmol, yield 93\%) was dried and used without further treatment. ${ }^{1} \mathrm{H}-\mathrm{NMR}$ (300 $\mathrm{MHz}, \mathrm{CDCl}_{3}$ ): $\delta=5.11-5.31$ (NHS, m), 4.63-4.92 $(1 \mathrm{H}, \mathrm{m}), 3.63(\mathrm{~s}, 2 \mathrm{H}), 1.50-1.61(\mathrm{~m}, 3 \mathrm{H})$.

\section{Preparation of $\mathrm{Fe}_{3} \mathrm{O}_{4}$}

Ferric acetate $\left[\mathrm{Fe}\left(\mathrm{CH}_{3} \mathrm{COO}\right)_{3} \times \mathrm{H}_{2} \mathrm{O}\right]$ was purchased from The Shepherd Chemical Company (Norwood, OH, USA), and ferrous acetate $\left[\mathrm{Fe}\left(\mathrm{CH}_{3} \mathrm{COO}\right)_{2}\right]$, and diethylene glycol $\left[\mathrm{O}\left(\mathrm{CH}_{2} \mathrm{CH}_{2} \mathrm{OH}\right)_{2}\right]$ were sourced from Sigma-Aldrich (St. Louis, MO, USA). All the chemicals were of reagent grade and used without any further purification. Iron oxide nanoparticles were synthesized using the following polyol method. Ferric acetate and ferrous acetate (stoichiometric $\mathrm{Fe}^{3+}$ to $\mathrm{Fe}^{2+}$ ratio of 2:1) were solubilized in diethylene glycol at $110^{\circ} \mathrm{C}$ for one hour under an inert atmosphere. The solution was heated to $180^{\circ} \mathrm{C}$ with a heating rate of $2^{\circ} \mathrm{C}$ per minute and then kept at $180^{\circ} \mathrm{C}$ for 3 hours. Finally, the dispersion was air-cooled to room temperature and stored. The black suspension contained about $1 \% \mathrm{w} / \mathrm{w}$ of iron oxide (sample A).

After the first synthesis, suitable quantities of solvent and precursors were added at room temperature at halfconcentration (sample A) and the heating cycle was repeated (one hour at $110^{\circ} \mathrm{C}$ and 3 hours at $180^{\circ} \mathrm{C}$ ) in order to obtain larger particles. Repeating the same procedure three times, each time using particles prepared in the previous step as initial seeds, the final magnetic material concentration was $1 \%$. The sample gave stable colloidal dispersions in polar solvents such as glycol as a result of the stabilizing effect of the solvent itself. The pattern matched the one expected for the iron oxide spinel phases, ie, $\mathrm{Fe}_{3} \mathrm{O}_{4}$ magnetite and/or gamma- $\mathrm{Fe}_{2} \mathrm{O}_{3}$ maghemite. Because these phases cannot be discriminated by $\mathrm{X}$-ray powder diffraction in nanocrystalline samples due to the line-broadening of the peaks, we assumed that the samples were preferentially made of magnetite due to their deep black color. Nevertheless, this assumption has no consequences on the resulting analysis and discussion. The crystallite size was determined from the five main diffraction peaks of the diffraction pattern using the Scherrer

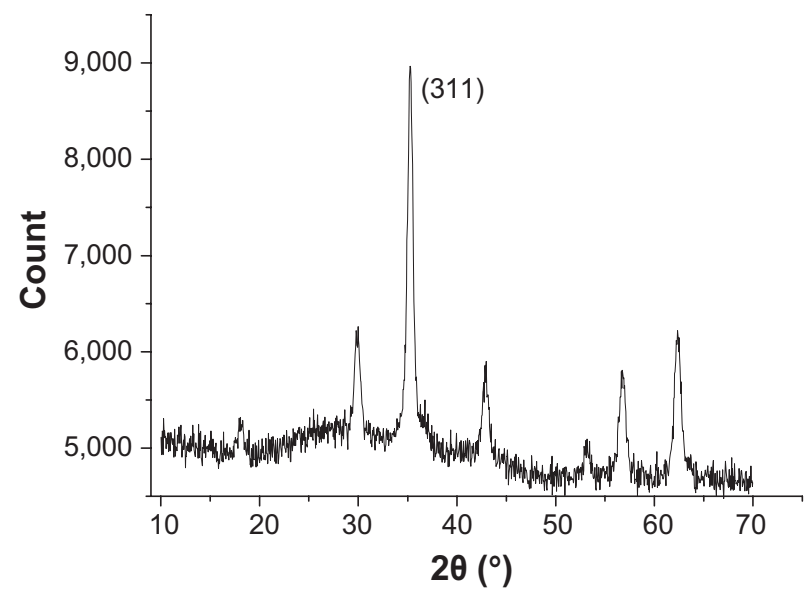

Figure SI X-ray diffraction pattern of the $\mathrm{Fe}_{3} \mathrm{O}_{4}$ dispersion sample.

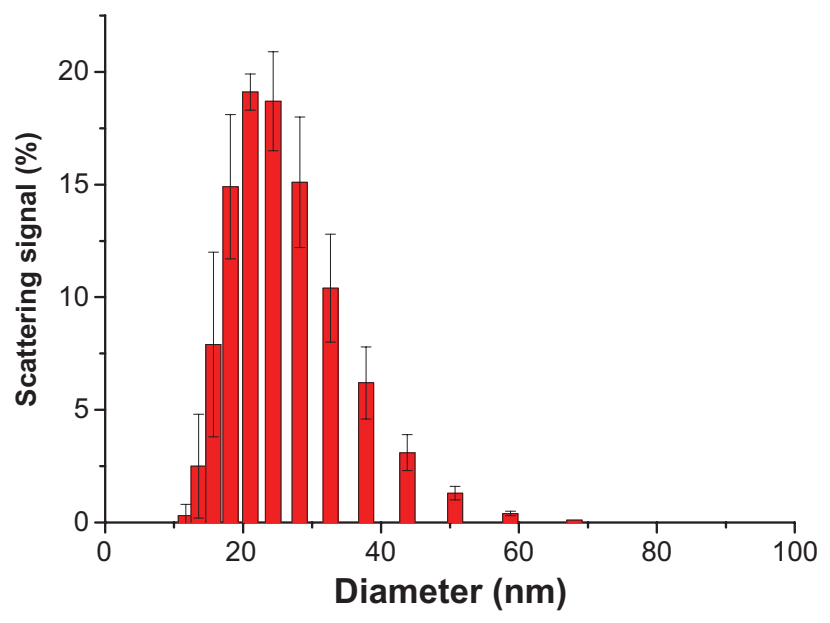

Figure S2 Log-normal size distribution of $\mathrm{Fe}_{3} \mathrm{O}_{4}$ by dynamic light scattering.

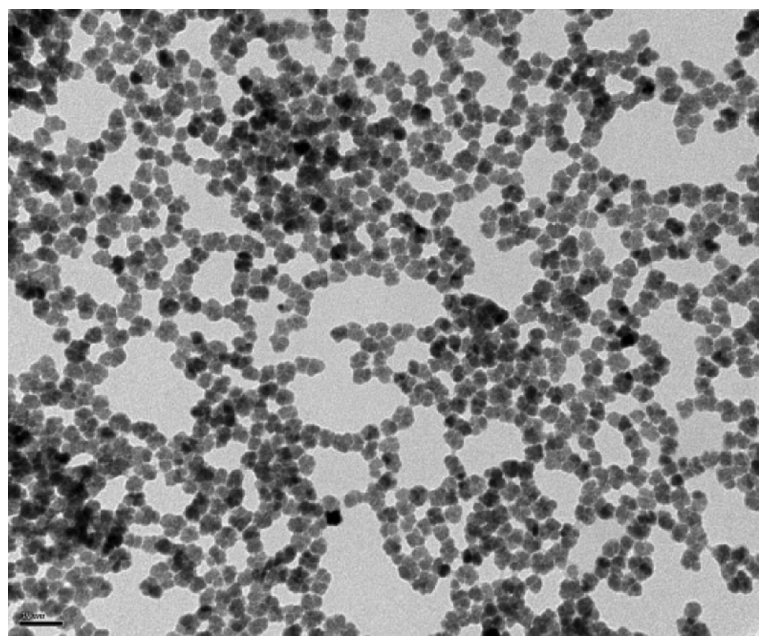

Figure S3 Transmission electron micrograph of magnetite dispersion (image obtained courtesy of a collaboration with the Laboratoire de Chimie des Polymères Organiques Bordeaux in the framework of the European Project NANOTHER, $7 \mathrm{wp})$. Scale bar, $50 \mathrm{~nm}$. 
method, and each coherent crystalline cluster had an average size of $12.0 \pm 0.9 \mathrm{~nm}$ (see Figure S1).

The suspension was characterized by dynamic light scattering in order to gain insights into the hydrodynamic diameter of the nanoparticles. The sample shows a relatively narrow log-normal size distribution (Figure S2) centered at $23.2 \pm 1.2 \mathrm{~nm}$ (polydispersity index $0.10 \pm 0.04$ ). Figure $\mathrm{S} 3$ shows representative bright field transmission electron microscopic images of the magnetite sample, indicating the presence of flower-like inorganic particles homogeneously dispersed in the organic medium. Magnetization measurements for $\mathrm{Fe}_{3} \mathrm{O}_{4}$ are reported in Figure S4.

\section{Magnetization measurements}

\section{Preparation of $\mathrm{Fe}_{3} \mathrm{O}_{4}-\mathrm{I}$}

A suspension of $\mathrm{Fe}_{3} \mathrm{O}_{4}$ in diethylene glycol (90 g, $\mathrm{Fe}_{3} \mathrm{O}_{4}=0.952 \mathrm{~g}, 4.1 \mathrm{mmol}$ ) was sonicated for 2 hours and

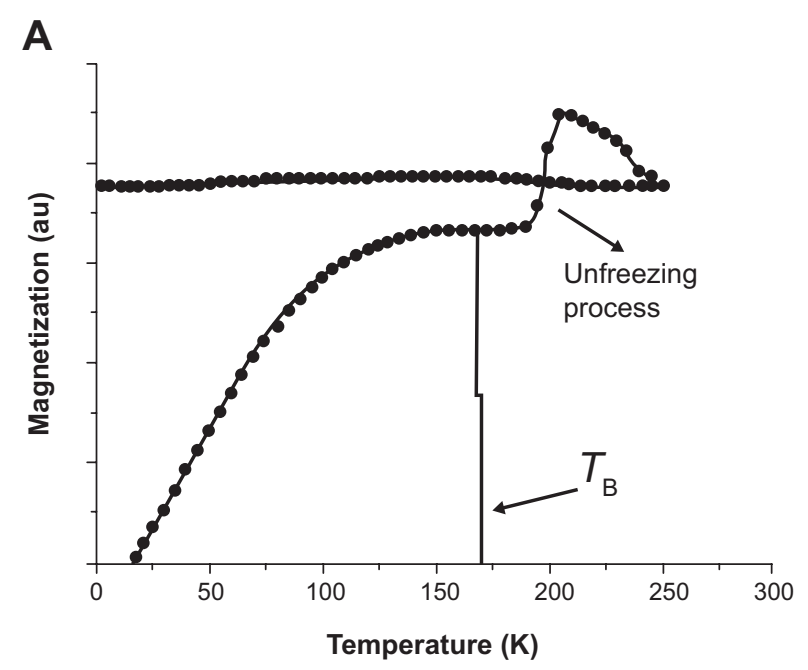

B

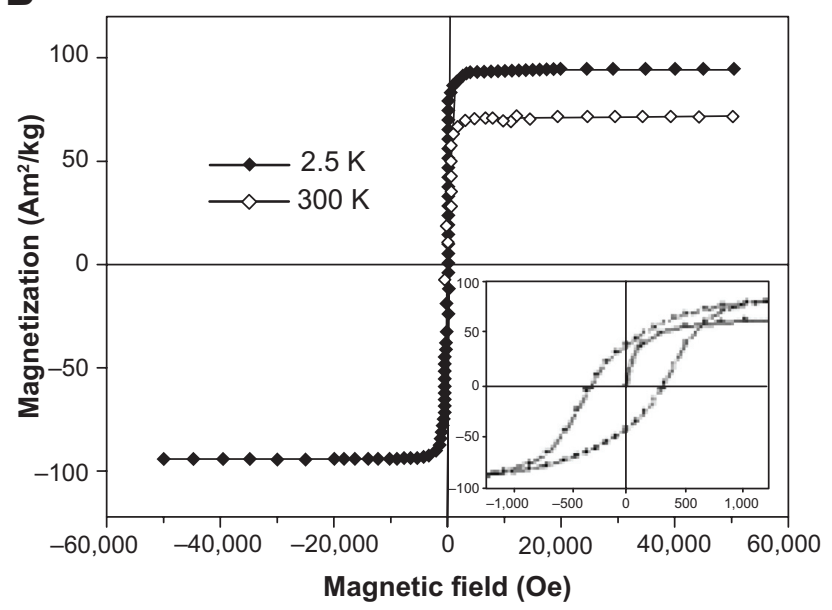

Figure S4 Magnetic characterization of the inorganic core of iron oxide $\left(\mathrm{Fe}_{3} \mathrm{O}_{4}\right)$ nanoparticles.

Notes: (A) Zero field-cooling/field-cooling magnetization curves performed with a 50 Oe probe field and (B) magnetization curves at low $(2.5 \mathrm{~K})$ and room (300 K) temperature. Low field range details are shown in the inset.

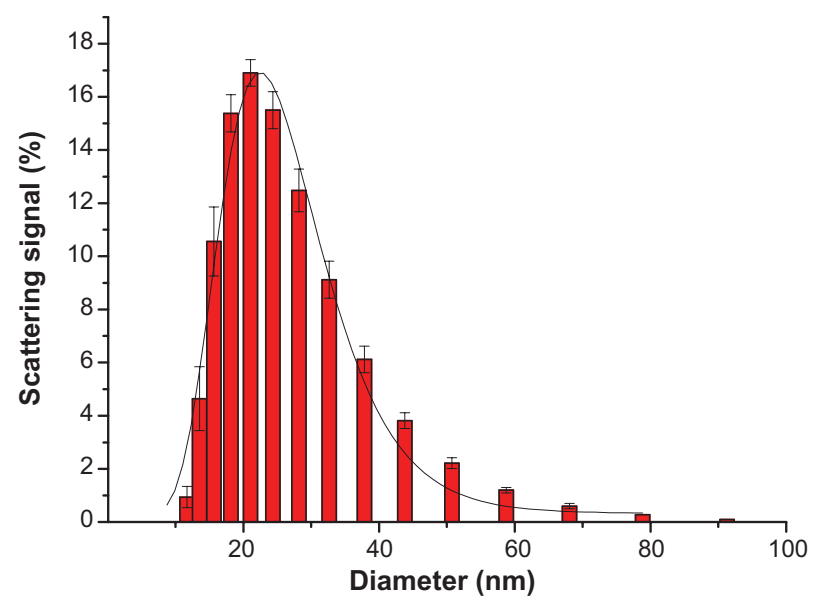

Figure S5 Log-normal size distribution of $\mathrm{Fe}_{3} \mathrm{O}_{4}-\mathrm{I}$ by dynamic light scattering.

then slowly added (addition time 10 minutes) to a solution of ligand $1(1.12 \mathrm{~g}, 4.1 \mathrm{mmol})$ dissolved in $30 \mathrm{~g}$ of absolute ethanol. The system was left to react under mechanical stirring for 48 hours at room temperature. Next, the solution was dialyzed (Pellicon XL, cut-off $100 \mathrm{kDa}$ ), adding $144 \mathrm{~mL}$ of ethanol $95 \%$ and washing with $360 \mathrm{~mL}$ of absolute ethanol; the purified dispersion was concentrated to a final volume of $20 \mathrm{~mL}$. Finally, the dispersion was diluted with $180 \mathrm{~g}$ of acetone to obtain the final $\mathrm{Fe}_{3} \mathrm{O}_{4}-1$. Dynamic light scattering showed a hydrodynamic radius of $25.6 \pm 0.3 \mathrm{~nm}$ and a polydispersity index value of $0.19 \pm 0.01$ (Figure S5). Finally, Infrared analysis was also carried out (Figure S6).

\section{Preparation of $\mathrm{Fe}_{3} \mathrm{O}_{4}-\mathrm{I}-\mathrm{PNPS}$}

To a solution of $0.5 \mathrm{~g}$ of PLGA- $b$-PEG-COOH (PLGA 43 $\mathrm{kDa}$, PEG $3 \mathrm{kDa}, 0.010 \mathrm{mmol}$ ) were dissolved in a $90 \mathrm{~mL}$ of acetone, then mixed to a dispersion of $\mathrm{Fe}_{3} \mathrm{O}_{4}-1$ in acetone $(160 \mathrm{~mL}$ at $0.39 \% \mathrm{wt}$ in iron oxide, corresponding to about $0.5 \mathrm{~g}$ of $\left.\mathrm{Fe}_{3} \mathrm{O}_{4}\right)$. Formation of hybrid $\mathrm{Fe}_{3} \mathrm{O}_{4}-1$-PNPs was achieved by the nanoprecipitation method: two streams of fluid (the acetone organic dispersion of $\mathrm{Fe}_{3} \mathrm{O}_{4}-1$ and PLGA$b$-PEG-COOH and $2.5 \mathrm{~L}$ of phosphate-buffered solution in a volumetric ratio of $1 / 10$ ) were mixed together under a constant flux into a mixing cell with vigorous stirring, and the so-formed mixture was continually removed by the mixing cell and recovered. The so-formed dispersion was then dialyzed (Cogent M system, Pellicon membrane 2 Mini, cut-off $100 \mathrm{kDa}$ ) in order to remove the organic phase using 7.5 L of phosphate-buffered aqueous solution; a final volume of $500 \mathrm{~mL}$ was then obtained after a first concentration. The system was again concentrated (Pellicon XL, cutoff $500 \mathrm{kDa}$ ) to a final volume of $40 \mathrm{~mL}$ and filtered through a syringe filter (Millipore Sterivex, $0.22 \mu \mathrm{m}$, polyethersulfone 


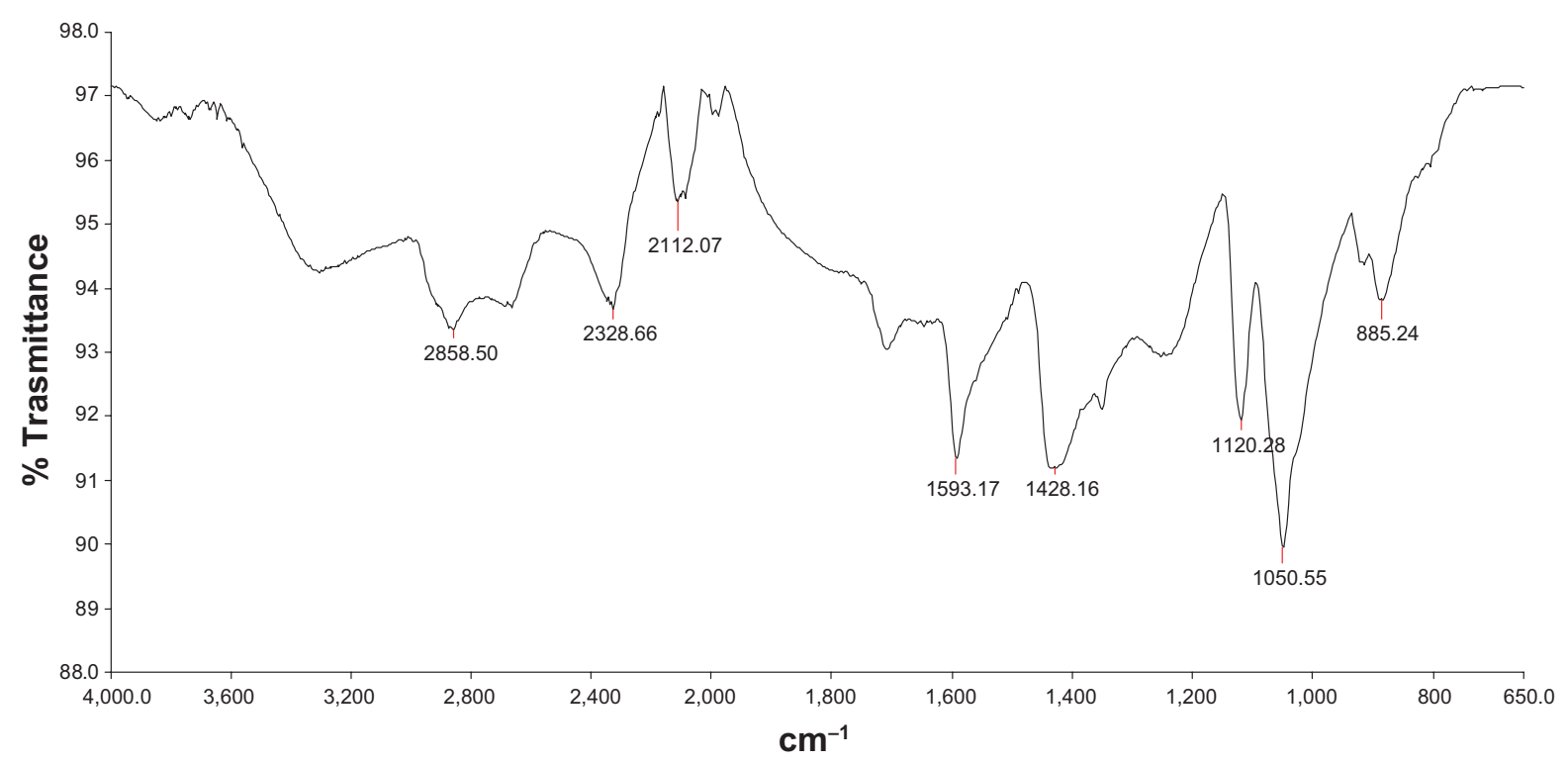

Figure S6 Infrared analysis of $\mathrm{Fe}_{3} \mathrm{O}_{4}-\mathrm{I}$

membrane). Inductively coupled plasma mass spectrometry showed an iron oxide concentration of $10 \mathrm{mg} / \mathrm{mL}$ in the final sample. Dynamic light scattering showed a hydrodynamic radius of $60.5 \pm 0.9 \mathrm{~nm}$, with a polydispersity index value of $0.15 \pm 0.02$ and a zeta potential of $-42.8 \pm 1.1 \mathrm{mV}$ (see Figures S7 and S8).

\section{Preparation of $\mathrm{Fe}_{3} \mathrm{O}_{4}-\mathrm{I}-\mathrm{PNP}-\mathrm{hEGFR}$}

To a $2 \mathrm{mg} / \mathrm{mL}$ stirred dispersion of $\mathrm{Fe}_{3} \mathrm{O}_{4}-1$-PNPs in phosphate-buffered solution, $1 \mathrm{mM}(30 \mathrm{~mL})$ EDAC, $(3.22 \mathrm{~mL}$ of a $0.028 \mathrm{M}$ solution, molar ratio of nanoparticles to EDAC, 1:100) and N-hydroxysulfosuccinimide (sulfoNHS, $3.91 \mathrm{~mL}$ of a $0.23 \mathrm{mM}$ solution, molar ratio of nanoparticles to sulfo-NHS, 1:1) were added, and the mixture was allowed to stand for 40 minutes. It was then diluted with phosphate-buffered saline $(113 \mathrm{~mL})$ and a solution of hEGFR (4 mL, $2.5 \mathrm{mg} / \mathrm{mL}$ ) was added. The system was left to react for 24 hours at room temperature. Next, it was dialyzed by washing with $200 \mathrm{~mL}$ of $1 \mathrm{mM}$ phosphate-buffered solution and concentrated phosphate-buffered solution (Pellicon XL, cut-off $500 \mathrm{kDa}$ ) to obtain a final volume of $10 \mathrm{~mL}$ that was finally filtered with a syringe filter (Millipore Sterivex, $0.22 \mu \mathrm{m}$, polyethersulfone membrane). Dynamic light scattering showed a mean diameter of $77.8 \pm 2.1 \mathrm{~nm}$, a polydispersity index value of $0.12 \pm 0.01$, and a zeta potential value of $-34.5 \pm 0.3 \mathrm{mV}$ (Figure S9). Inductively coupled plasma mass spectrometry revealed an iron oxide concentration of $2.6 \mathrm{mg} / \mathrm{mL}$. The main magnetic properties (iMr, MS, and $\mathrm{HC}$ ) of the nanoconstructs were found not to be affected by the subsequent synthetic treatments (Figure S10).
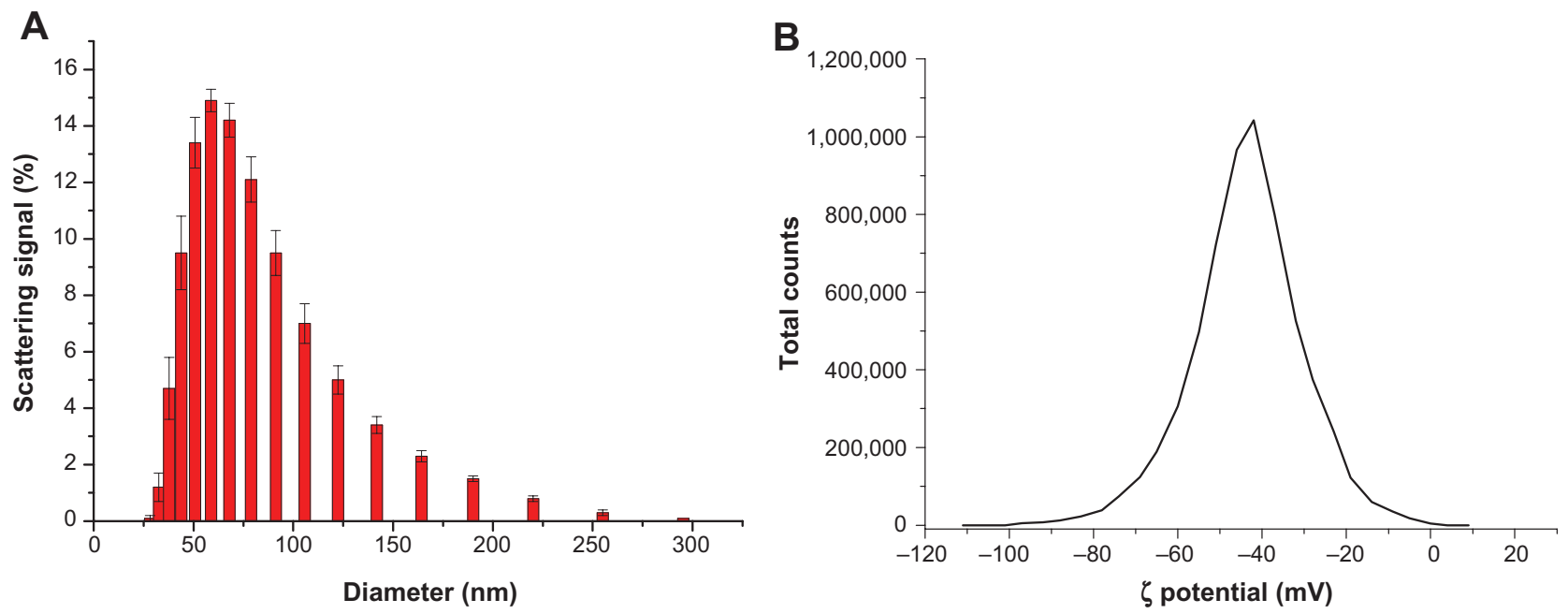

Figure S7 Log-normal size distribution by dynamic light scattering (A) and analysis of zeta potential for $\mathrm{Fe}_{3} \mathrm{O}_{4}-\mathrm{I}-\mathrm{PNPs}(\mathbf{B})$.

Abbreviation: PNPs, polymeric nanoparticles. 

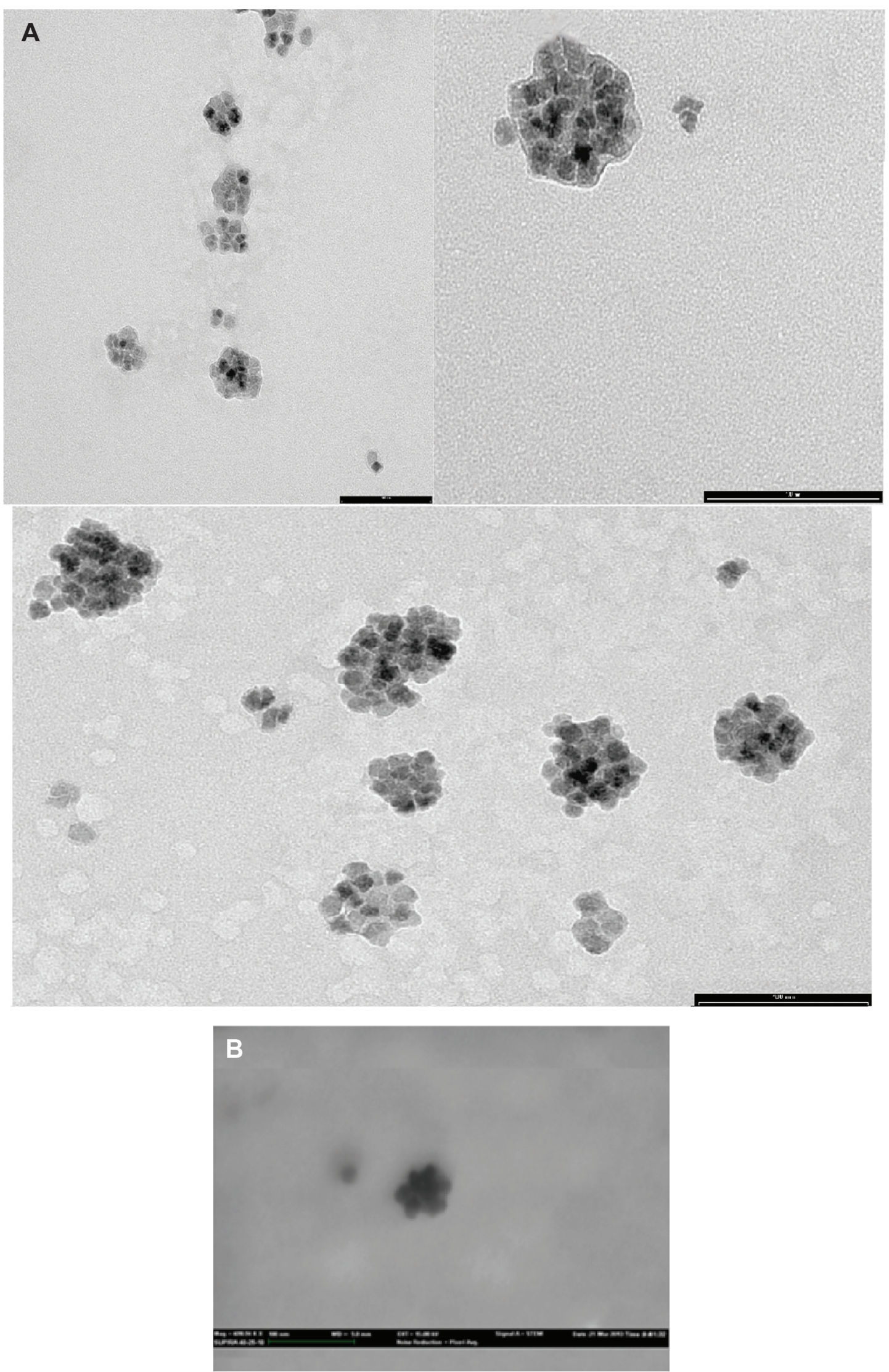

Figure S8 (A) Transmission electron micrographs and (B) scanning transmission electron micrograph of $\mathrm{Fe}_{3} \mathrm{O}_{4}-1-\mathrm{PNPs}$. Scale bar, $100 \mathrm{~nm}$ Abbreviation: PNPs, polymeric nanoparticles. 

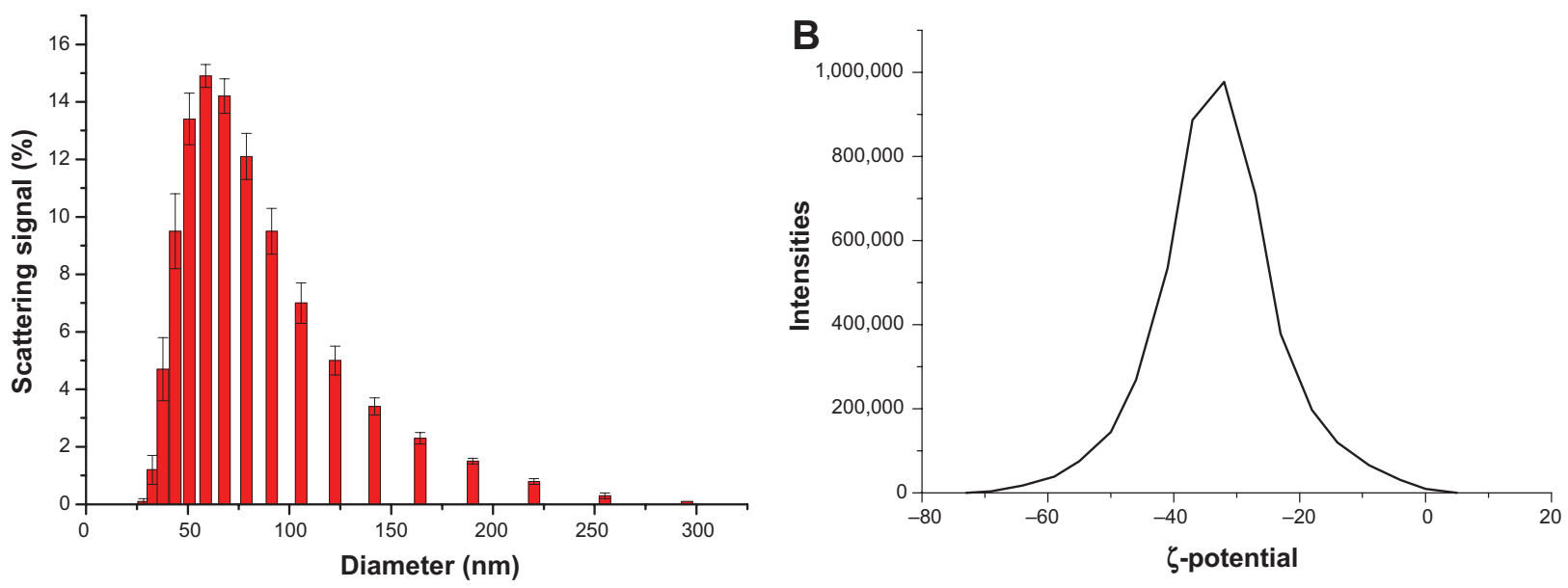

Figure S9 Log-normal size distribution by dynamic light scattering (A) and analysis of zeta potential of $\mathrm{Fe}_{3} \mathrm{O}_{4}-\mathrm{I}$-PNPs-hEGFR (B). Abbreviations: hEGFR, human epidermal growth factor; PNPs, polymeric nanoparticles.

\section{Antibody activity}

Antibody activity was verified by flow cytometry. The antibody at $2.030 \mathrm{mg} / \mathrm{mL}$ (dilution 1/1,000 in phosphate-buffered saline, $1 \%$ bovine serum albumin, and $0.1 \%$ sodium azide) was able to mark the MDA-MB-231 human breast adenocarcinoma cell line and the DAOY human neuroglioblastoma cell line.

\section{Quantification of monoclonal antibody}

Ultraviolet-visible analysis for quantification of monoclonal antibodies was carried out using the bicinchoninic acid test for three samples: $\mathrm{Fe}_{3} \mathrm{O}_{4}-1$-PNPs-hEGFR $\left(2.6 \mathrm{mg} / \mathrm{mL}\right.$ in iron oxide); $\mathrm{Fe}_{3} \mathrm{O}_{4}-1-P N P s$ (diluted up to $3.0 \mathrm{mg} / \mathrm{mL}$ in iron oxide) without the grafted monoclonal

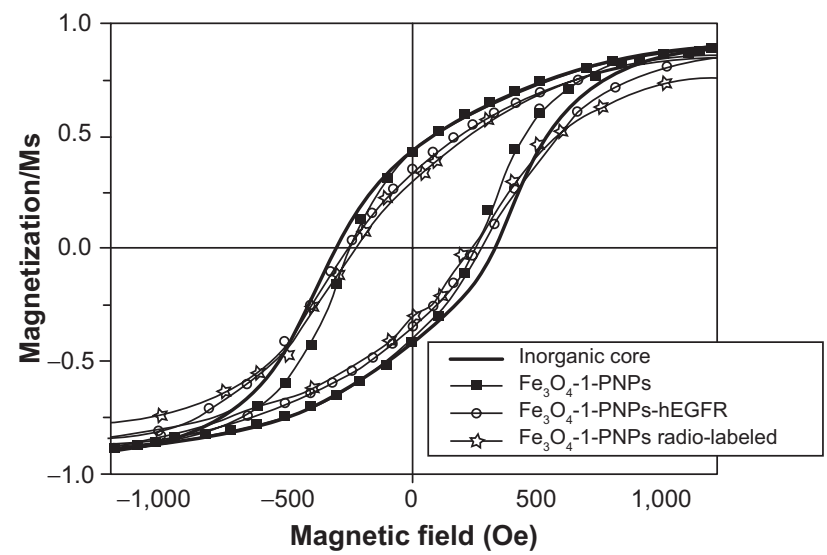

Figure SIO Comparison of the magnetization curve of the inorganic core and those of the hybrid nanoparticles functionalized by hEGFR and then radiolabeled by ${ }^{99} \mathrm{Tc}$. The curves are collected at low temperature $(2.5 \mathrm{~K})$ and normalized to the corresponding saturation magnetization.

Abbreviations: hEGFR, human epidermal growth factor receptor; PNPs, polymeric nanoparticles. antibody in order to evaluate the signal ascribed to analytical interferences; and wash waters collected during the purification step. Each measurement was repeated three times. According to the results (see Figure S13), the concentration of monoclonal antibody in the wash waters was below the detection limit and could therefore be considered negligible. Since strong coloration of the suspension $(\lambda 564 \mathrm{~nm})$ was recorded for the nontargeted sample $\mathrm{Fe}_{3} \mathrm{O}_{4}-1$-PNPs, probably due to the interference of iron reacting with the solution reagents, it was necessary to subtract the signal due to the nontargeted micelles from that recorded for the monoclonal antibody-grafted nanoparticles in order to achieve the correct concentration of the monoclonal antibody attached to the hybrid nanoparticles (see Figures S11-S13).

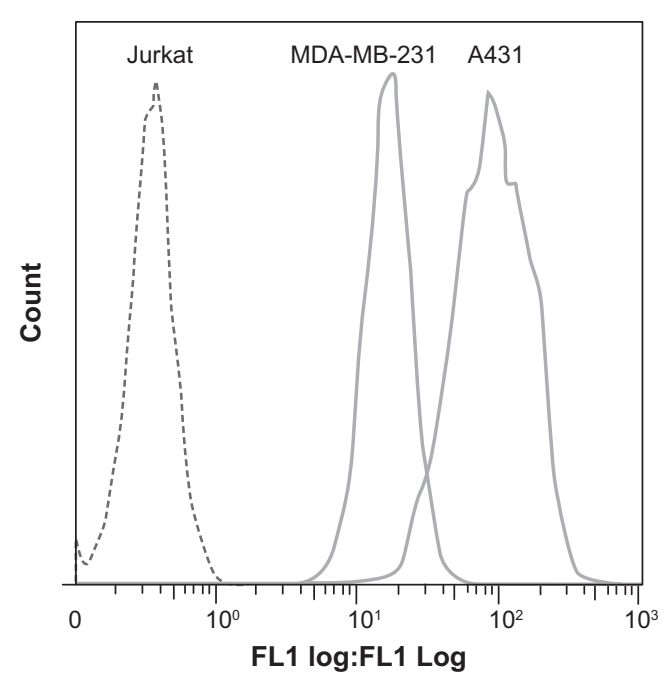

Figure SII Check for overexpression of epidermal growth factor receptor in Jurkat, MDA-MB-23I, and A43I cell lines. 


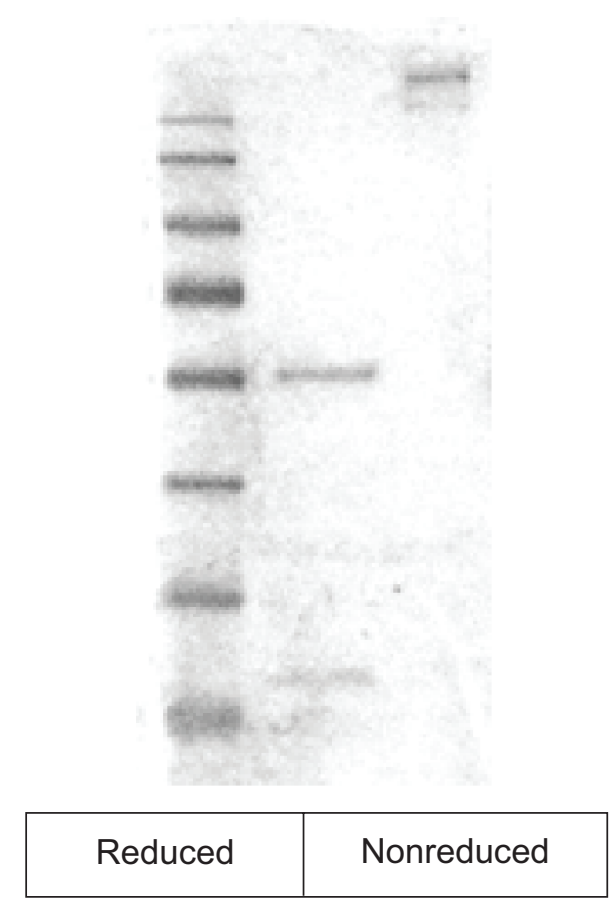

Figure SI 2 Electrophoresis analysis of the purified antibody.

The concentration achieved at the first analysis was normalized with respect to the concentration of inorganic phase (3.0 mg/mL and $2.6 \mathrm{mg} / \mathrm{mL}$ for $\mathrm{Fe}_{3} \mathrm{O}_{4}-1$-PNPs and $\mathrm{Fe}_{3} \mathrm{O}_{4}-1$ PNPs-hEGFR, respectively). By subtracting the contribution of the nontargeted $\mathrm{Fe}_{3} \mathrm{O}_{4}-1-\mathrm{PNPs}$, we obtained:

$$
\begin{aligned}
C{ }_{\mathrm{Fe}_{3} \mathrm{O}_{4}-1-\mathrm{PNPs}-\mathrm{hEGFR}}^{*} & =C_{\mathrm{Fe}_{3} \mathrm{O}_{4}-1-\mathrm{PNPs}-\mathrm{hEGFR}}^{N}-C_{\mathrm{Fe}_{3} \mathrm{O}_{4}-1-\mathrm{PNPs}}^{N} \\
& =(846.8-296.0)[\mu \mathrm{g} / \mathrm{mL}]=551[\mu \mathrm{g} / \mathrm{mL}]
\end{aligned}
$$

thus leading to a weight ratio of monoclonal antibody/ $\mathrm{Fe}_{3} \mathrm{O}_{4}=0.21$.

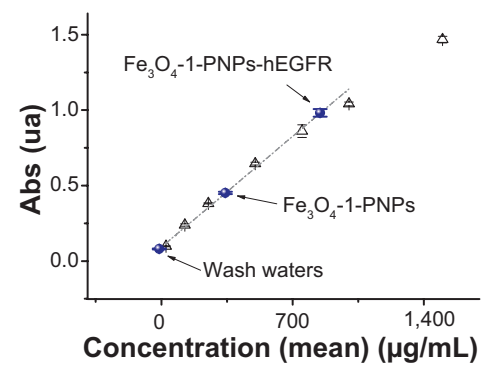

\begin{tabular}{llll}
\hline & $\begin{array}{l}\text { Absorbance } \\
(\mathbf{u a})\end{array}$ & $\begin{array}{l}\text { Concentration } \\
(\boldsymbol{\mu g} / \mathrm{mL})\end{array}$ & $\begin{array}{l}\text { Concentration normalized } \\
(\boldsymbol{\mu g} / \mathrm{mL})\end{array}$ \\
\hline Wash water & 0.080 & $-11.4 \pm 0.002$ & - \\
$\mathrm{Fe}_{3} \mathrm{O}_{4}-1-\mathrm{PNPS}$ & 0.451 & $341.5 \pm 0.008$ & 296.0 \\
$\mathrm{Fe}_{3} \mathrm{O}_{4}-1-\mathrm{PNPS}-\mathrm{hEGFR}$ & 0.981 & $846.8 \pm 0.02$ & $846.8 \pm 0.026$ \\
\hline
\end{tabular}

Figure SI3 Determination of the monoclonal antibody attached to the hybrid nanoparticles.

Abbreviations: hEGFR, human epidermal growth factor receptor; PNPs, polymeric nanoparticles; Abs, absorbance.

\section{Verification of activity of anti-EGFR antibody}

The assays were carried out in a 96-well plate. First, $20 \mu \mathrm{L}$ of Alamar blue (1:10) were added to each well. The plates were then incubated at $37^{\circ} \mathrm{C}$ and fluorescence was monitored by an enzyme-linked immunosorbent assay reader. Viability assays performed with the anti-EGFR antibody demonstrated that the antibody as a drug alone did not affect viability in several cell lines, including HT29, HCT116, SKBR3, and MBMDA231.

The results obtained with the targeted and nontargeted nanocarrier + anti-EGFR + hyperthermia in HT29 and HCT116 cell lines indicated slightly decreased cell viability in both cell lines, but only when the monoclonal antibody was conjugated. A toxic effect was observed only when the highest concentration of targeted nanoparticle with the anti-EGFR antibody was used (cell viability of $60 \%$ for $1.8 \mathrm{mg} / \mathrm{mL}$ of nanocarrier and $400 \mu \mathrm{g} / \mathrm{mL}$ of anti-EGFR) in comparison with the nontargeted ones at the same concentration, showing that the efficacy of the monoclonal antibody was retained.

\section{In vivo biodistribution and hyperthermic treatment $\mathrm{Fe}_{3} \mathrm{O}_{4}$ - I-PNPs-hEGFR- ${ }^{99} \mathrm{Tc}$}

Radiolabeling of hybrid nanoformulations with ${ }^{99 \mathrm{~m}} \mathrm{Tc}$ was performed directly using $\mathrm{SnCl}_{2}$ as the reducing agent, as described in Psimadas et al. ${ }^{1}$ Quality control was performed by ascending instant thin layer chromatography silica gel using acetone as well as a mixture of pyridine:acetic acid:water $(3: 5: 1.5)$ as mobile phase solvents. Using the above systems, we could determine the free ${ }^{99} \mathrm{mcO}_{4}^{-}$ and the reduced/hydrolyzed ${ }^{99 \mathrm{~m}} \mathrm{Tc}$ in the final solution and calculate the percentage of the $\mathrm{Fe}_{3} \mathrm{O}_{4}-1$-PNPs-hEGFR- ${ }^{-9} \mathrm{~m} \mathrm{Tc}$ formed under these conditions. The strips were counted for radioactivity in a gamma imager and percentage labeling efficiency was calculated.

\section{Stability of $\mathrm{Fe}_{3} \mathrm{O}_{4}$-I-PNPs-hEGFR-99 Tc}

Stability of the ${ }^{99 \mathrm{~m}} \mathrm{Tc}$-radiolabeled targeted nanocarriers containing magnetic nanoparticles was determined in vitro in pentetic acid and His solutions and in human serum by the instant thin layer chromatography silica gel technique.

\section{Cell culture}

A431 cells were grown in high glucose Dulbecco's Modified Eagle's Medium supplemented with 10\% 
(volume/volume [v/v]) fetal bovine serum, 1\% L-glutamine, and $1 \%$ penicillin/streptomycin. Cells were incubated in a controlled humidified atmosphere containing $5 \% \mathrm{CO}_{2}$ at $37^{\circ} \mathrm{C}$ and were subcultured weekly after being detached from the flask surface by trypsin/ethylenediaminetetraacetic acid solution.

\section{In vitro stability}

The results of instant thin layer chromatography silica gel analysis are presented in Figure S14. The displacement that occurred after the pentetic acid challenge was expected due to the strong chelating ability that pentetic acid has for ${ }^{99 \mathrm{~m}} \mathrm{Tc}$. Various factors can affect the stability of radiolabeled $\mathrm{Fe}_{3} \mathrm{O}_{4}-$ 1-PNPs-hEGFR in conditions that mimic the biological environment, such as assembly morphology, size, or surface charge, which is mainly attributed to the coating. All the above may result in a suitable or a less convenient "environment" for the formation of the ${ }^{99 \mathrm{~m}} \mathrm{Tc}$-complex. ${ }^{2}$

\section{Biodistribution and imaging results}

The radiolabeled nanoparticles were injected into tumorbearing mice, which were sacrificed at 60 minutes, 90 minutes, and 24 hours post injection. Three animals were used at each time point. Their organs were removed, weighed, and measured using a gamma counter, in order to obtain indicative biodistribution time points as shown in Figure S15 (upper panel). Concentration in the tumor was higher than $1 \%$ per organ, and the analysis per gram showed that it was much higher than the concentration in normal tissue. Finally, the concentration in the blood and kidneys suggests that the nanoparticles remained in the blood circulation for a longer

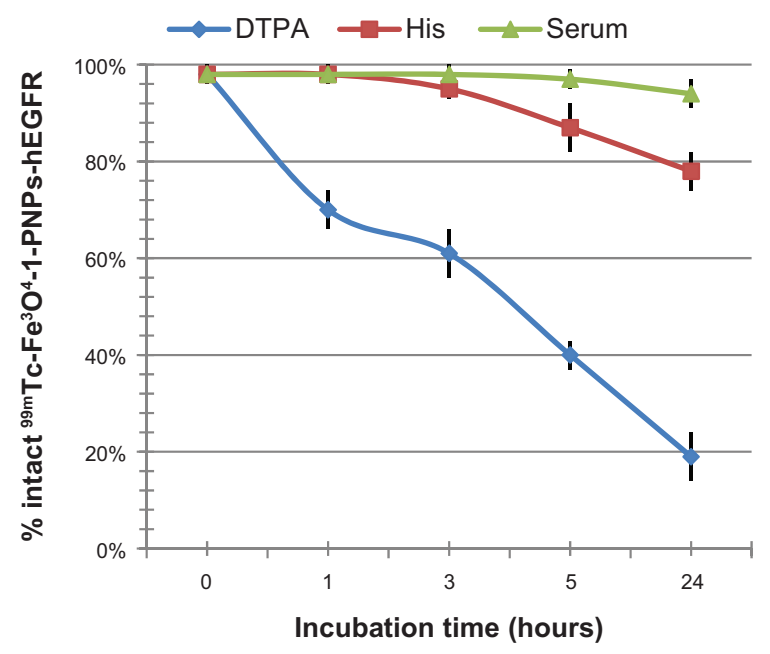

Figure SI4 Instant thin layer chromatography silica gel results showing the intact $\mathrm{Fe}_{3} \mathrm{O}_{4}$-I-PNPs-hEGFR- ${ }^{99 \mathrm{~m}} \mathrm{Tc}$ - following DTPA, His, and serum stability studies after incubation at $37^{\circ} \mathrm{C}$.

Abbreviations: hEGFR, human epidermal growth factor receptor; PNPs, polymeric nanoparticles; DTPA, pentetic acid. time. A similar analysis was done when $\mathrm{Fe}_{3} \mathrm{O}_{4}-1-\mathrm{PNPs}-$ ${ }^{99 \mathrm{~m}} \mathrm{Tc}$ without hEGFR were injected into normal mice and is summarized in Figure S15 (bottom panel). In this case, four time points at 3 minutes, 60 minutes, 90 minutes, and 5 hours post injection are provided. Again, three animals were used at each time point. The results show a significant uptake in the liver and spleen.

Additional semiquantitative information could be extracted from the in vivo data, as described in the original paper. The total intensity in these regions of interest was divided by the total mouse intensity to provide a value proportional to the percentage of radiolabeled nanoparticle concentration per organ. The results for the organs that could be identified are given in Figure S16.

The results show a good correlation with the ex vivo biodistribution, and additionally provide several time points from the first minutes post injection. For $\mathrm{Fe}_{3} \mathrm{O}_{4}-1$-PNPshEGFR-99m Tc, a maximum and almost stable concentration was observed in the liver, which is merged with the spleen, given that those organs cannot be separated in the planar image. Some concentration in the lungs is also observed, indicating the potential presence of some aggregates. Kidney activity was stable and close to $4 \%$, while a slow but
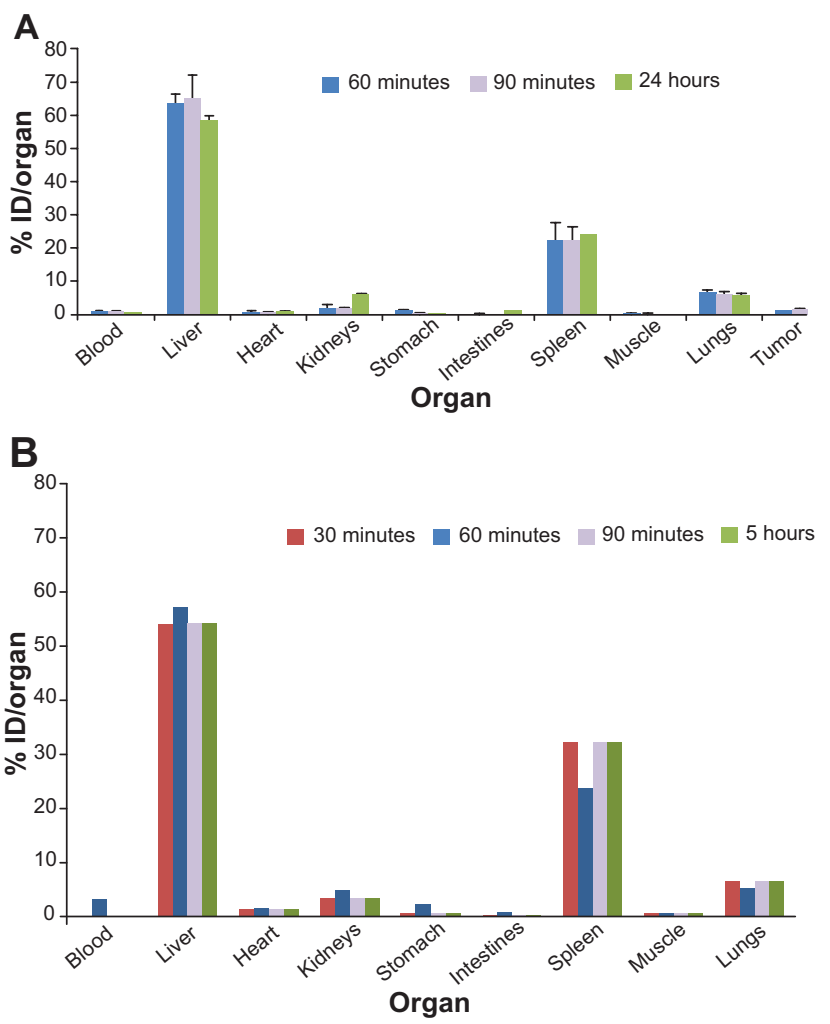

Figure $\mathrm{SI} 5$ Biodistribution of $\mathrm{Fe}_{3} \mathrm{O}_{4}-\mathrm{I}-\mathrm{PNPs}-\mathrm{hEGFR}-{ }^{99 \mathrm{~m}} \mathrm{Tc}$ in tumor-bearing mice $(\mathrm{n}=3)(\mathbf{A})$ and $\mathrm{Fe}_{3} \mathrm{O}_{4}-\mathrm{I}-\mathrm{PNPs}-{ }^{99 m} \mathrm{Tc}(\mathbf{B})$.

Abbreviations: hEGFR, human epidermal growth factor receptor; PNPs, polymeric nanoparticles; ID, injected dose. 


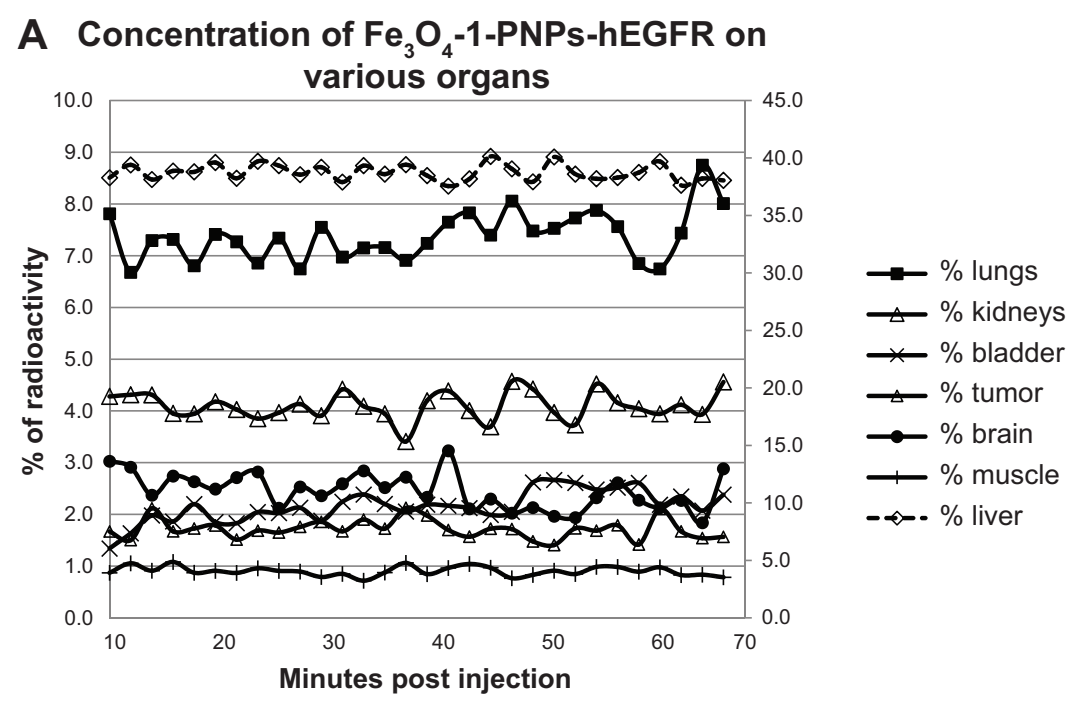

\section{$\mathrm{B}$ Concentration of $\mathrm{Fe}_{3} \mathrm{O}_{4}-1-\mathrm{PNPs}$ on various organs}

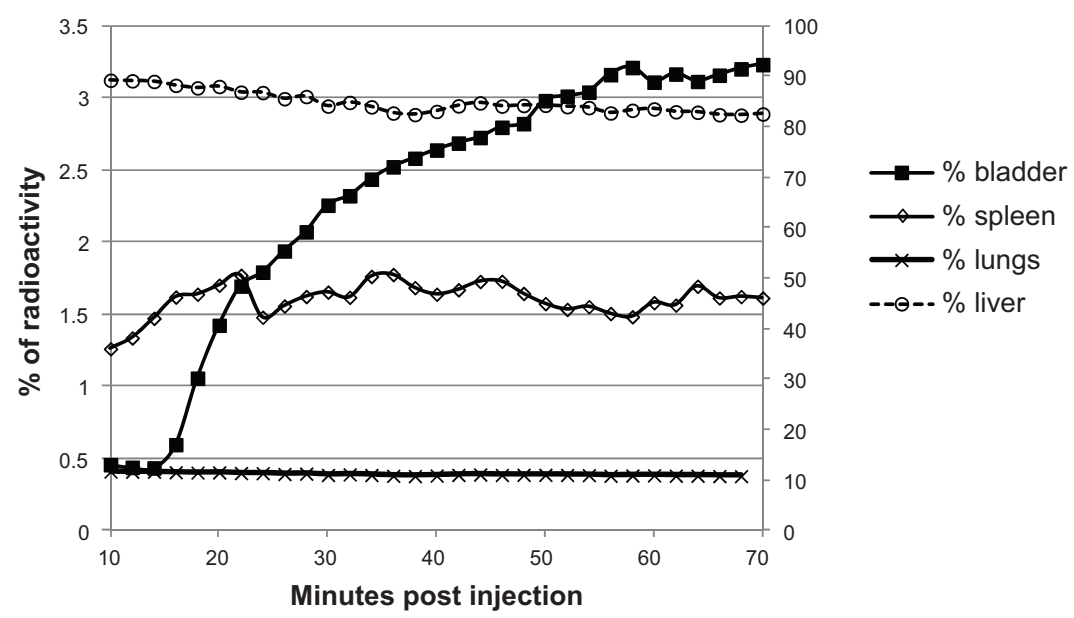

Figure SI 6 Percentage of radioactivity concentration using regions of interest in liver, muscle, brain, tumor, bladder, kidneys, and lungs in a dynamic study of Fe $\mathrm{O}_{4}-\mathrm{I}_{-\mathrm{PNPs}}$ hEGFR- ${ }^{99 \mathrm{~m}} \mathrm{Tc}$ in an A43I tumor-bearing mouse (A). Similar analysis in a normal mouse injected with $\mathrm{Fe}_{3} \mathrm{O}_{4}-\mathrm{I}-\mathrm{PNPs}-{ }^{99 \mathrm{~m}} \mathrm{Tc}(\mathbf{B})$. Regions of interest were applied on successive 2-minute frames. The liver is plotted on a secondary axis.

Abbreviations: hEGFR, human epidermal growth factor receptor; PNPs, polymeric nanoparticles.

continuous increase in the bladder showed that the nanoparticles continued to circulate in the blood. An interesting concentration of $\sim 2.5 \%$ was noted in the head region, which may indicate concentration in the brain and should be explored further. Finally, the concentration in the tumor was $\sim 2 \%$, which is significantly higher than that found in normal muscle tissue ( 1\%, see Figure S16).

\section{References}

1. Psimadas D, Baldi G, Ravagli C, et al. Preliminary evaluation of a $99 \mathrm{mTc}$ labeled hybrid nanoparticle bearing a cobalt ferrite core: in vivo biodistribution. J Biomed Nanotechnol. 2012;8:575-585.

2. Psimadas D, Oliveira H, Thevenot J, et al. Polymeric micelles and vesicles: biological behavior evaluation using radiolabeling techniques. Pharm Dev Technol. 2014;19(2):189-193.

\section{Publish your work in this journal}

The International Journal of Nanomedicine is an international, peerreviewed journal focusing on the application of nanotechnology in diagnostics, therapeutics, and drug delivery systems throughout the biomedical field. This journal is indexed on PubMed Central, MedLine, CAS, SciSearch ${ }^{\circledR}$, Current Contents ${ }^{\circledR} /$ Clinical Medicine,
Journal Citation Reports/Science Edition, EMBase, Scopus and the Elsevier Bibliographic databases. The manuscript management system is completely online and includes a very quick and fair peer-review system, which is all easy to use. Visit http://www.dovepress.com/ testimonials.php to read real quotes from published authors. 